\title{
A METHODOLOGY FOR CHARACTERIZING THE HYDRAULIC EFFECTIVENESS OF AN ANNULAR LOW-PERMEABILITY BARRIER
}

Víctor Vilarrasa ${ }^{1,2}$, Anna Jurado-Elices ${ }^{1,2}$, Estanislao Pujades-Garnés ${ }^{1,2}$, Enric Vázquez-Suné2 \& Jesús Carrera ${ }^{2}$

${ }^{1}$ GHS, Dept Geotechnical Engineering and Geosciences, Universitat Politecnica de Catalunya, UPC-Barcelona Tech, Jordi Girona 1-3, 08034 Barcelona, Spain. ${ }^{2}$ GHS, Institute of Environmental Assessment \& Water Research (IDAEA), CSIC, Jordi Girona 18-26, 08034 Barcelona, Spain. 


\begin{abstract}
Excavation works in urban areas are often performed in compartments enclosed by means of grouting or structural walls that provide hydraulic isolation and mechanical stability. These functions are sensitive to the presence of discontinuities (apertures in the enclosing wall), which may cause flooding of the excavation and dragging of soil particles. The objective of this work is to develop a methodology to evaluate the hydraulic efficiency of the manmade low-permeability barrier and to identify possible discontinuities, so as to repair them. To this end, we consider the drainage of a circular excavation enclosed by an annular low-permeability barrier that may present an aperture. We solve the problem numerically in dimensionless form. The hydraulic effectiveness of the enclosing system can be easily characterized by monitoring pumping rate and drawdown. However, several piezometers are usually needed to localize an aperture. The proposed method for characterizing the effectiveness of a lowpermeability barrier is applied to several cases. Although little information was available in one case, the method presented here gives results that agree well with those obtained from a numerical model. In another case, in which data from several piezometers was available, the region of an existing aperture in the low-permeability barrier was localized.
\end{abstract}




\section{INTRODUCTION}

Several underground infrastructures have been constructed in the Barcelona urban area in the last decade. Most of them have been excavated below the water table. The present study was motivated by the hydrogeological monitoring on the final section of a High Speed Train tunnel construction entering Barcelona and on the metro stations of line L-9 placed South of Barcelona in the Llobregat Delta (Figure 1). The High Speed Train tunnel was excavated in mine, following mainly the Belgian method of tunneling (Tatiya, 2005). Jet-grouting treatment was conducted to improve the heterogeneous soil which the tunnel passes through (Vilarrasa et al., 2009). The metro line L-9 is excavated with a Tunneling Boring Machine (TBM) and presents circular stations that are excavated within diaphragm walls (Jurado-Elices et al., 2009). The excavation was drained to work in dry conditions in both cases.

Deep excavations should be drained in the presence of groundwater. These excavations are usually delimited by grouting or structural walls forming closed compartments in densely populated urban areas. Theoretically, closed compartments allow an effective drainage by pumping so as to excavate in dry conditions (Pickles et al., 2003; Shaqour \& Hasan, 2008; Xu et al., 2009) and minimize settlements outside the excavation zone (Knight et al., 1996; Forth, 2004). However, the enclosure frequently contains discontinuities or apertures (Mihalis et al., 2004; Candeias et al., 2007; Croce \& Modoni, 2007; Flora et al., 2007). For instance, overlapping jet-grouting columns will create a tight enclosure. However, the columns may display diameter variability and/or vertical deviation (Croce \& Modoni, 2007), which can ultimately cause apertures in the jet-grouting curtain. Modoni et al. (2006) indicate that different jet-grouting propagation mechanisms exist during execution, depending on the soil material, i.e. gravel, sand or clay. High permeability gravel should lead to large column 
diameters, while the diameter decreases with the square root of its shear strength for sand and clay. Cementing or large boulders may cause "shadow" effects, leaving soil portions groutless. Heterogeneity of the soil will lead to variability of the jet-grouting diameter along the vertical direction, which may lead to apertures. Other construction techniques, such as diaphragm walls, pile walls and sheet piles, although made of reinforced concrete, may also present apertures in the joints, allowing the groundwater to enter in the closed compartments (Knight et al., 1996).

Apertures may facilitate dragging of soil particles. Caving outside the excavation may result if the dragged soil volume is large. This could eventually cause ground collapse, as happened in the construction of the high speed train in Barcelona or a metro station in Cologne on 3 March 2009 (Rowson, 2009), where the Archive was destroyed. The probability that these undesired events occur can be evaluated using risk assessment analysis (Bolster et al., 2009).

To avoid disasters, the quality of the grouting or structural walls should be quantified. The jet-grouting column diameter can be determined using the jet-sounding technique (Fang et al., 2006), which confirms the diameter of the columns by sound propagation within the jet-grouting. Alternatively, it can be estimated by means of temperature measurements, which allow the determination of the diameter of columns by matching the measurements to a cement-based materials model that accounts for the hydration process (Pichler et al., 2003; Brandstätter et al., 2005). Knowing the jetgrouting column's diameter permits the determination of whether the soil treatment coincides with the designed one, thus evaluating the probability that apertures exist. Geophysical techniques, such as vertical seismic profile, tomography and electromagnetics, can be employed to quantify the degree of continuity of structural walls made of concrete. However, these techniques are not widely applied. 
Instead, hydraulic methods can be used to determine the presence of apertures in a low-permeability barrier. Unfortunately, the topic is not well developed. Numerical models are useful to predict and interpret the groundwater response to pumping regardless of the geometric complexity of the study area (Rienzo et al., 2008; Thierry et al., 2009; Vilarrasa et al., 2009), but they cannot be generalized and have to be specially elaborated for each site. Alternatively, well hydraulics provides with some analogues that might be of interest for civil works, in which determining the efficiency of a manmade low-permeability barrier is crucial. For example, a tunnel can be represented as a linear strip, or a circular metro station can be approximated as a disc. The former case has been studied by Butler \& Liu (1991), who found that changes in drawdown depend on the linear strip transmissivity for a limited duration of time. The latter case has been analysed both by pumping in the center of the disc (Butler, 1988), and outside the disc (Wheatcraft \& Winterberg, 1985; Butler \& Liu, 1993). Butler (1988) found that the hydraulic properties of the disc, when pumping in its center, can only be determined before the cone of depression moves across the discontinuity, similarly to the linear strip case. This suggests that the effective transmissivity of a low-permeability barrier can be determined by pumping tests. It also suggests that measuring the drawdown at the beginning of the pumping test is of crucial importance to characterize the heterogeneities that are present in the aquifer. Nevertheless, none of the previously studied geometries describes an annular low-permeability barrier, which would represent, for instance, a circular low-permeability barrier created so as to excavate in its interior.

The objective of this study is to develop a methodology to: (1) determine the hydraulic effectiveness of an annular low-permeability barrier, which can present an 
aperture, while pumping inside, and (2) identify and delimit the possible existence of apertures, so as to repair them.

\section{METHODOLOGY}

\subsection{Problem Setup}

A perfectly confined homogeneous aquifer, with an annular low-permeability barrier around the excavation zone and a fully penetrating well in the center (Figure 2c) are considered to solve the problem in a generalized form. The aquifer is assumed infinite. Figure 2 displays an outline of the geometry, both for the case without aperture (Figure 2a) and with aperture in the low-permeability barrier (Figure 2b). Here, for the sake of simplicity, we assume that only one aperture exists. Unlike the case of the closed ring, when an aperture in the low-permeability barrier exists, the drawdown is not the same in all orientations. For this reason, three orientations have been chosen to present the results: orientation 1 coinciding with the aperture, orientation 2 opposite to the aperture and orientation 3 perpendicular to the previous orientations.

Two alternatives have been considered regarding the pumping well: constant flow rate and constant head.

\subsection{Governing Equations}

Drawdowns caused by pumping are governed by the flow equation, which in dimensionless form and radial coordinates reads (Bear, 1972)

$$
\frac{1}{r_{D}} \frac{\partial}{\partial r_{D}}\left(r_{D} T_{D} \frac{\partial h_{D}}{\partial r_{D}}\right)+\frac{1}{r_{D}} \frac{\partial}{\partial \theta}\left(\frac{T_{D}}{r_{D}} \frac{\partial h_{D}}{\partial \theta}\right)=S_{D} \frac{\partial h_{D}}{\partial t_{D}}
$$

with prescribed head boundary conditions at the outer (infinite) boundary

$$
r_{D} \rightarrow \infty, h_{D}=0,
$$


and either prescribed flow in the well

$$
\frac{1}{2 \pi} r_{w_{D}} \int_{0}^{2 \pi} \frac{\partial h_{D}}{\partial r_{D}} d \theta=1
$$

or prescribed head in the well

$$
h_{D}=1
$$

The dimensionless variables considered are

$$
r_{D}=\frac{r}{R}, t_{D}=\frac{t}{t_{c}}, \theta, T_{D}=\frac{T_{R}}{T}, S_{D}=\frac{S_{R}}{S}, h_{D}=\frac{h}{h_{c}}
$$

where

$$
\chi_{R}=\left\{\begin{array}{l}
\chi, 0 \leq r_{D} \leq 1, \theta \in(0,2 \pi] \\
\chi, 1<r_{D}<1+e / R, \theta \in[-\arcsin (a / R), \arcsin (a / R)] \\
\chi, 1<r_{D}<1+e / R, \theta \in(\arcsin (a / R), 2 \pi-\arcsin (a / R)) \\
\chi, r_{D} \geq 1+e / R, \theta \in(0,2 \pi]
\end{array},\right.
$$

where $r$ is the radial distance [L], $R$ is the inner radius of the low-permeability barrier [L], $t$ is time [T], $\theta$ is the angular aperture, $\chi$ is either $T$ or $S, T$ is the aquifer transmissivity and $T^{\prime}$ is that of the low-permeability barrier $\left[\mathrm{L}^{2} \mathrm{~T}^{-1}\right], S$ is the aquifer storage coefficient and $S^{\prime}$ is that of the low-permeability barrier [-], $h$ is the piezometric head [L], $e$ is the thickness of the low-permeability barrier [L], $a$ is the semi-aperture length, $h_{c}=Q /(2 \pi T)$ or $h_{c}=s_{w}$ is the characteristic head for a constant pumping rate or a constant head in the pumping well respectively $[\mathrm{L}], Q$ is the pumping rate $\left[\mathrm{L}^{3} \mathrm{~T}^{-1}\right], s_{w}$ is the drawdown in the well, and $t_{c}=S R^{2} / T$ is the characteristic time [T]. $Q_{c}=h_{c} T$ is the characteristic pumping rate for a constant head in the pumping well. The suffix $D$ indicates a dimensionless variable, $w$ the well and $c$ indicates a characteristic variable.

The storage coefficient of the low-permeability barrier is very small compared with that of the aquifer, as well as the transmissivity. In addition, the thickness of the 
barrier is small compared to the inner radius of the enclosure. This leads to a pseustationary flow across the barrier. Thus, the Thiem (1906) solution for drawdown applies in the low-permeability barrier, and the dimensionless head drop across it, assuming that $e / R$ is small, becomes (see Appendix A)

$$
\Delta h_{b_{D}}=\gamma=\frac{T e}{T^{\prime} R} .
$$

This drawdown in the low-permeability barrier can be related to the skin effect concept (Agarwal et al., 1970). If the enclosure did not exist, the dimensionless drawdown between both sides of the barrier would be $\Delta h_{D}=e / R$. Thus, the presence of the enclosure produces an additional drawdown of

$$
\sigma=\frac{\left(T-T^{\prime}\right) e}{T^{\prime} R}
$$

where $\sigma$ is the skin effect defined by Agarwal et al. (1970). Note that for a transmissivity of the low-permeability barrier much smaller than that of the aquifer, the skin effect $\sigma$ and $\gamma$ defined in Equations (7) and (8) are almost identical.

In addition to the skin effect, the excavation zone acts as a large diameter well and will have a well-bore, i.e. the excavation zone, storage effect (Papadopulos \& Cooper, 1967). However, here the well-bore is filled with soil, so the storage is proportional to the storage coefficient. This modifies the dimensionless parameter $C_{D}$ given by Papadopulos \& Cooper (1967), resulting in

$$
C_{D}=\frac{r_{c}^{2}}{2 r_{w}^{2}},
$$

where $r_{c}$ is the casing radius and $r_{w}$ that of the well screen. In this case, both radii are the same, yielding $C_{D}=1 / 2$. These two concepts apply only for the case of an enclosure without aperture. 


\subsection{Numerical Simulation}

The problem of pumping in the center of an annular low-permeability barrier that presents an aperture does not have an analytical solution. For this reason, the problem is solved using numerical models.

The models are circular and dimensionless. The outer boundary is placed at a dimensionless distance of 2000 from the pumping well. The thickness of the lowpermeability barrier is constant and equal to 0.2 . The mesh in the outer boundary has an element size of 150 . This size progressively decreases towards the center of the model. The barrier is discretized with 4 rows of elements of 0.05 and the 6 elements, $n$, forming the pumping well have a size, $R_{e}$, of 0.01 . This means that the apparent radius, $r_{a p}$, of the pumping well is (see Appendix B)

$$
r_{a p}=\frac{R_{e}}{e^{\frac{2 \pi}{n \tan (\pi / n)}}}=\frac{0.01}{6.134}=1.63 \cdot 10^{-3} .
$$

Several numerical simulations, considering different aperture angles and transmissivity ratios, were carried out using the finite element method (FEM) code TRANSIN IV (Medina et al., 2004). The hydraulic parameters were introduced accordingly to the dimensionless form of the problem. The storage coefficient of the low-permeability barrier is considered to be very small in comparison with that of the aquifer (30 orders of magnitude smaller). The considered angles of aperture in the barrier go from 0.0 to $1.0 \mathrm{rad}$ with $0.1 \mathrm{rad}$ increments, and also the angles of aperture 2.0, 3.0, 5.0 and $10.0 \mathrm{rad}$. The transmissivity ratio ranges from 1 , homogeneous aquifer, to $10^{-5}$, a barrier with very low-permeability. To analyze the drawdown curves, we use the dimensionless head drop across the low-permeability barrier $\gamma=T e /\left(T^{\prime} R\right)$ defined in Equation (7), which captures all the relevant parameters of the problem. 


\section{RESULTS AND DISCUSSION}

\subsection{Prescribed Pumping Flow Rate}

\subsubsection{Low-Permeability Barrier without Aperture}

Drawdowns for the case of perfect enclosure, i.e. without an aperture, are shown in Figure 3 (inside the enclosure, $r_{D}=0.9$ ) and 4 (outside the enclosure, $r_{D}=1.25$ ). Drainage evolution can be divided into three periods. At early times $\left(t_{D}<0.1 t_{c}\right)$, drawdown evolves as if the barrier was not present. Usually, this period will not last very long. From there on, the excavation zone behaves as a large diameter well (Papadopulus \& Cooper, 1967) with a skin effect (Agarwal et al., 1970). That is, drawdown evolves linearly with time as the enclosure is emptied

$$
s-s_{0}=\frac{Q\left(t-t_{0}\right)}{\pi R^{2} S},
$$

where $s_{0}$ is the drawdown at the beginning of the period $\left(s_{0} \approx(Q /(2 \pi T)) \ln \left(R / r_{w}\right)\right)$ and $t_{0}$ is the time when this period starts $\left(t_{0}=0.1 S R^{2} / T\right)$. For practical purpose, both $s_{0}$ and $t_{0}$ can be taken as zero. Expressing Equation (11) in dimensionless form yields

$$
s_{D}=2 t_{D}
$$

Thus, the drawdown evolves with a slope of 1 in log-log scale during the emptying of the enclosure (Figure 3b). This period continues until drawdown inside the barrier is sufficient to cause a flow rate across it (Equation 7) equal to the pumping rate. Combining Equation (7) with Equation (12) gives

$$
t_{2_{D}}-t_{0_{D}}=\frac{T e}{2 T^{\prime} R}
$$

where $t_{2_{D}}$ is the dimensionless time at which the second period ends. Eventually, for $t_{D}>t_{2_{D}}$, drawdown evolves as Jacob's curve with 


$$
s_{D}=s_{2_{D}}+\frac{1}{2} \ln \left(\frac{2.25 T t}{S R^{2}}\right)=s_{2_{D}}+m \log \left(2.25 t_{D}\right)
$$

which displays a straight line in the semilog plot of slope $m=1.15$ (Figure $3 a$ ).

Outside the enclosure, drawdown does not respond in the first period since it only affects the excavation zone. After this, the change of head between both sides of the barrier increases as the excavation zone empties. Thus, the flow across the lowpermeability barrier progressively increases until it becomes significant and drawdown outside the low-permeability barrier starts. The flow that crosses the low-permeability barrier equals the pumping flow rate once the second period finishes, i.e. the dimensionless time in Equation (12). After a transient period, the drawdown cone stabilizes in the whole geometry, evolving as Jacob's drawdown with

$$
s_{D}=s_{2_{D}}+\frac{1}{2} \ln \left(\frac{2.25 T t}{S r^{2}}\right)=s_{2_{D}}+m \log \left(2.25 \frac{t_{D}}{r_{D}^{2}}\right),
$$

which displays a straight line in the semilog plot of slope $m=1.15$ (Figure 4a).

Note that in this third period the drawdown equals the homogeneous case (Figure 4). This fact coincides with the results presented by Butler (1988), who found that the effect that a circular heterogeneity has on the drawdown, when pumping in its centre, can only be detected for a limited time. Thus, to determine the hydraulic properties of the low-permeability barrier is necessary to measure the drawdown at early times once the pump starts.

\subsubsection{Low-Permeability Barrier with Aperture}

In general, an aperture in a low-permeability barrier can be considered significant when the flow through it is equal or greater than that across the rest of barrier. The effect of a significant aperture can be observed in Figure 5. Figure 6 shows that the drawdown outside the enclosure, at a dimensionless distance of 1.25 , for an 
aperture of $0.0017 \mathrm{rad}$ is almost identical in all orientations to the case without aperture. Instead, drawdown varies significantly depending on the orientation for apertures greater than $0.0035 \mathrm{rad}$. Thus, the critical aperture is in the range of 0.0017 to 0.0035 rad (Figure 6).

The slope of the drawdown in the semilog representation for long times is the same for all orientations, coinciding with the slope of the case in which there is no aperture in the barrier (Figure 6a). These results agree with those obtained by Meier et al. (1998), who found that the effective transmissivity of the aquifer can be estimated using the Jacob's method for long pumping times and that the orientations that are better connected with the pumping well have greater drawdown. Thus, if only one piezometer is available and no previous pumping test exists, it cannot be said whether the enclosure is open or not. However, making two pumping tests, one previous to the construction of the low-permeability barrier and another afterwards, give enough information to determine whether there is a significant aperture and how close it is from the observation point. If the observed drawdown is bigger than those previous to the existence of the enclosure, there is an aperture and is close to the observation point. However, if the drawdown is lower, it means that an aperture exists but its situation cannot be determined. Therefore, more observation points should be drilled to localize the aperture, so as to repair it.

\subsection{Prescribed Head in the Well}

\subsubsection{Low-Permeability Barrier without Aperture}

In civil works, the groundwater table should remain at least one meter below the excavation level. The process of dewatering the excavation zone with a constant head in the well is similar to the case in which the pumping rate is constant. Nevertheless, as the 
head in the well is fixed, the amount of water that will be able to flow through the barrier depends on the dimensionless head drop across the low-permeability barrier $\gamma$ and will change with time (Figure 7). Thus, for low-permeability barriers with high $\gamma$ the excavation zone is rapidly emptied, but outside the barrier, the drawdown is insignificant and the pumping rate decreases rapidly to very low values. This is of especial interest because a well designed and constructed low-permeability barrier will allow to easily dewatering the excavation zone, and will have a negligible impact on the aquifer, as the water table would not be significantly affected by the pumping.

\subsubsection{Low-Permeability Barrier with Aperture}

Figure 8 shows that the drawdown outside the barrier is no longer negligible when the low-permeability barrier presents apertures. Furthermore, drawdown is significantly greater than the case without aperture in all orientations. Thus, the water table will be affected by the drainage of the excavation, which may have negative side effects on the surrounding environment. The magnitude of the aperture has a great effect on the drawdown. Thus, one piezometer can give valuable information about the magnitude and location of the aperture. For long times, the slope of the drawdown curve in the semilog representation is the same for all orientations (Figure 8a). This slope corresponds to the effective transmissivity of the aquifer, and increases for increasing angle of aperture. This is because for higher angles of aperture, the pumping flow rate in the well increases to maintain the prescribed head (Figure 9). Furthermore, the pumping rate for a given angle of aperture decreases with time. Figure 9 can be helpful in designing the drainage system because it gives the range of flow rate that has to be pumped. 


\section{APPLICATION PROCEDURE}

We propose the following procedure to detect and localize apertures in lowpermeability barriers when dewatering its interior for excavation purposes:

1) Perform a pumping test previous to the construction of the low-permeability barrier, at least with one piezometer outside the future location of the enclosure.

2) Start the drainage of the excavation zone as if it were a pumping test, controlling pumping rate and drawdown with a high frequency.

3) Evaluate the existence of apertures by curve fitting. If apertures exist, delimit their situation and drill more piezometers if necessary, so as to repair them.

4) Monitor pumping rate and drawdown periodically, and repeat step (3).

However, in some situations there is little information available. Then, the efficiency of the low-permeability barrier can be determined by knowing at least the hydraulic head on both sides of the low-permeability barrier and the pumping rate. Assuming long times, i.e. the pumping rate is the same as the flow that crosses through the low-permeability barrier, the effective transmissivity of the low-permeability barrier, $T^{\prime}$, can be determined from

$$
Q_{b}=\alpha \Delta h_{b}=L \frac{T^{\prime}}{e} \Delta h_{b}
$$

where $Q_{b}$ is the flow that crosses through the low-permeability barrier, $\alpha$ is the leakage coefficient of the low-permeability barrier, $\Delta h_{b}$ is the change of head between both sides of the low-permeability barrier, $L$ is the length of the low-permeability barrier, and $e$ is the low-permeability barrier thickness. 


\section{EXAMPLES}

\subsection{High Speed Train Tunnel Construction}

An application of this method has been performed on the final section of the High Speed Train tunnel construction entering Barcelona. The geology is formed by quaternary alluvial fills placed above a substrate of Pliocene very low-permeable marls (Figure 10a). In this zone, the tunnel is placed below the water table, and is excavated intersecting a high-permeability gravel-sandy clayey layer that needs to be drained. Furthermore, a low-permeability clay layer is placed just above the tunnel and acts as an aquitard, giving additional groundwater to the layer placed below the aquitard when it is dewatered (Hart et al., 2005; Trinchero et al., 2007).

Due to the characteristics of the soil, a jet-grouting treatment was decided to be performed to improve its mechanical properties and reduce its permeability. The jetgrouting treatment was formed by rectangles of $20.0 \mathrm{~m}$ long and $10.1 \mathrm{~m}$ wide, with a thickness, $e$, of $2.5 \mathrm{~m}$ (Figure 10b) crossing the whole thickness of the aquifer. One of these rectangles was monitored. For long times, in which a steady-state has been reached, the pumping rate was $2.9 \mathrm{l} / \mathrm{s}$, and the head inside and outside the enclosure were -5.0 and $0.8 \mathrm{~m}$ above sea level respectively. Assuming that the pumping rate in the wells coincides with the flow that passes through the jet-grouting curtain, the transmissivity of the jet-grouting can be obtained substituting values in Eq. (16), resulting in a transmissivity of the jet-grouting of $3 \mathrm{~m}^{2} / \mathrm{d}$. In contrast, the aquifer transmissivity is $300 \mathrm{~m}^{2} / \mathrm{d}$ (Vilarrasa et al., 2009), which means that the $\gamma=31$. This value is lower than expected for a well performed jet-grouting treatment. Thus, it suggests the existence of apertures in the jet-grouting treatment. However, the apertures could not be localized due to the lack of available data. Apertures permit the flow of a significant amount of groundwater towards the excavation. This implies redesigning the 
drainage system and a head drop greater than expected outside the barrier. The latter gives rise to larger settlements than predicted initially in the surrounding of the excavation. If the new settlements are not acceptable (e.g. damage to buildings), some mitigations measures have to be carried out.

Additionally, a numerical model of the aquifer through which the High Speed Train tunnel is excavated, including the jet-grouting treatment, was created to support decision making (Vilarrasa et al., 2009). The calibration of this model gave a transmissivity of the jet-grouting of $1 \mathrm{~m}^{2} / \mathrm{d}$ and of the aquifer of $305 \mathrm{~m}^{2} / \mathrm{d}$, which agrees with the interpretation of pumping test and field measures. Despite the fact that the geometry of the jet-grouting treatment is rectangular, instead of annular like the geometry presented in this paper, the agreement with the calibrated parameters suggests that this simplification is in the order of the approximations made in equation (16).

\subsection{Metro Stations of Line L-9}

The vast majority of the stations in the metro line L-9 are circular and some are rectangular. To excavate them, a circular diaphragm wall of reinforced concrete of $26 \mathrm{~m}$ in diameter is build. Not only has this wall a structural function, but also acts as a hydraulic barrier to prevent groundwater from entering inside the excavation zone. The hydraulic gradient across the low-permeability barriers when dewatering the excavation zone becomes very high (a head drop in the order of $30 \mathrm{~m}$ in a $1 \mathrm{~m}$ thick diaphram wall). Thus, open joints in the concrete walls may be critical for excavation purposes. We show two examples of stations. One of a circular station with constant pumping flow rate and an observation point outside the low-permeability barrier (Figure 11), and another of a rectangular station with constant hydraulic head inside the excavation and several observation points outside the low-permeability barrier (Figure 12). 
Geologically, the circular station (Foc Cisell) with a constant pumping rate (6.8 1/s), presents a shallow confined aquifer, an aquitard and a deep confined sandy aquifer, overlaying a clayed low-permeability Miocene substrate (Figure 11). The excavation level reaches the deep aquifer. The structural walls penetrate the low-permeability substrate, to minimize the groundwater entering the closed compartment that is drained.

Figure 13 displays the dimensionless drawdown measurements at an observation point outside the low-permeability barriers of this L-9 station. The daily measurements are compared with the drawdown curves shown in Figure 3b. It can be seen that $\gamma=$ $2 \cdot 10^{4}$, which means that the low-permeability barrier is effective and presents no apertures. Note that although the drawdown measurements are daily, there is no data for small dimensionless times, showing the necessity of measuring with a high frequency at the beginning of pumping.

In another station (Plaça Catalunya) (Figure 12), a constant head was maintained over three months in the excavation area. The geology is similar to the previous case, but with just one aquifer, and the structural walls penetrating into the underlying lowpermeability layer (Figure 12b). This station is rectangular, with an equivalent radius of $39 \mathrm{~m}$. The hydraulic head drop inside the enclosure was of $10.5 \mathrm{~m}$. Several observation points were measured daily inside and outside the excavation zone. The dimensionless drawdown of the external observation points is compared with the drawdown curves (Figure 14). Drawdown measurements from all observation points lay in the range of the $\gamma=100$ curve, except E8, which lay on the $\gamma=40$ curve. This slightly higher drawdown indicates that an aperture in the low-permeability barrier exists in the surroundings of the piezometer E8.

Figure 15 shows the dimensionless pumping rate, which compares well with the drawdown measurements. The measurements adjust to the $\gamma=80$ curve, which is 
coherent with the results obtained from the drawdown measurements. To maintain a constant head inside the enclosure a high pumping rate is necessary at early times. As the excavation zone is emptied over time, the pumping rate decreases until it reaches a steady state (Figure 15) in which the pumped water equals the amount of water entering through the barrier.

\section{DISCUSSION}

Deep excavations below the groundwater table should be drained. These excavations are usually delimited by grouting or structural walls, of low-permeability, forming closed compartments. However, these low-permeability barriers may contain apertures, letting the groundwater to flow easily towards the excavation zone. Well designed and constructed low-permeability barriers enable easy dewatering of the excavation zone and have a negligible impact on the groundwater table of the aquifer (Figures 3 and 4).

The effect of a low-permeability barrier without apertures on the drawdown, in response to a constant pumping rate, is detected for a limited time at an observation point outside the barrier (Figure 4). Afterwards, the drawdown is the same as the homogeneous aquifer. To characterize the hydraulic properties of the low-permeability barrier, drawdown and pumping rate have to be measured since pumping starts, especially at early times.

If the low-permeability barrier presents an aperture, the drawdown significantly varies depending on the orientation (Figure 5). When the pumping rate is constant, all the orientations have the same effective transmissivity for long pumping times, and the regions with better connection with the pumping well present greater drawdown (Figure $6)$. 
The pumping rate depends significantly on the effectiveness of the lowpermeability barrier when the head is fixed in the well (Figure 7). The effective transmissivity measured at the observation point increases with the angle of aperture when fixing the head in the well, because the pumping rate also increases (Figures 8 and 9).

The effectiveness of a low-permeability barrier can be easily characterized with a piezometer if the pumping rate and the drawdown are measured since pumping starts. If a pumping test previous to the construction of the low-permeability barrier is performed, apertures may be localized with just one piezometer. However, in general several piezometers are needed to localize an aperture.

This method was applied to several real cases. In one case in which little information was available, the method gave results that agreed well with the results obtained from a numerical model (Figure 10). In the cases where more data was available, a good characterization of the hydraulic effectiveness of the low-permeability barrier was obtained and it was even possible to localize the region of an existing aperture (Figures 12 and 14).

When there is evidence that apertures exist, the drainage system and the settlements outside the excavation zone should be recalculated. This is because more water will enter the enclosure and the head drop outside it will be greater than expected from the initial design. Then, the necessity of carrying out mitigation measures should be evaluated.

\section{CONCLUSIONS}

We study the drainage of a circular excavation enclosed by an annular lowpermeability barrier that may present an aperture. We present a methodology for 
characterizing the hydraulic effectiveness of this barrier and determining the location of possible apertures.

We solve the problem numerically in dimensionless form. The hydraulic effectiveness of the enclosing system can be easily characterized by performing two pumping test, one before and another after the construction of the low-permeability barrier, and monitoring pumping rate and drawdown in one piezometer placed outside the barrier. However, to localize an existing aperture, several piezometers are usually needed.

We apply the proposed method for characterizing the effectiveness of a lowpermeability barrier to several cases. Although little information was available in one case, the method presented here gives results that agree well with the results obtained from a numerical model. In another case, in which data from several piezometers was available, the region of an existing aperture in the low-permeability barrier was localized.

\section{ACKNOWLEDGEMENT}

The authors would like to acknowledge ADIF, GISA, GEOCONSULT and SACYR for their support throughout the hydrogeological monitoring of the civil works.

The first author wants to acknowledge the financial support from the Spanish Ministry of Science and Innovation (MCI) through the "Formación de Profesorado Universitario" program, and the "Colegio de Ingenieros Caminos, Canales y Puertos Catalunya" (CECCP). 


\section{REFERENCES}

Agarwal, R., G., Al-Hussainy, R. \& Ramey, H. J. J., 1970. An investigation of wellbore storage and skin effect in unsteady liquid flow. SPE Journal, 279-290.

Bear, J., 1972. Dynamics of Fluids in Porous Media. Elsevier, New York.

Bolster, D., Barahona, M., Dentz, M., Fernandez-Garcia, D., Sanchez-Vila, X., Trinchero, P., Valhondo, C. \& Tartakovsky, D. M., 2009. Probabilistic risk analysis of groundwater remediation strategies. Water Resources Research, 45, W06413, doi:10.1029/2008WR007551.

Brandstätter, C., Lackner, R. \& Mang, H. A., 2005. In situ temperature measurements provide new insight into the performance of jet grouting. Ground Improvement, 9 (4), 163-167.

Butler, J. J. J., 1988. Pumping tests in nonuniform aquifers - the radially symmetric case. Journal of Hydrology, 101, 15-30.

Butler, J. J. J. \& Liu, W. Z., 1991. Pumping tests in non-uniform aquifers - the linear strip case. Journal of Hydrology, 128, 69-99.

Butler, J. J. J. \& Liu, W., 1993. Pumping tests in nonuniform aquifers: the radially asymetric case. Water Resources Research, 29 (2), 259-269.

Candeias, M. A. S.; Brito, J. A. M.; Fernandes, M. y Lopes, P. G., 2007. Jet - grouting solution to link a tunnel to a cut - and - cover excavation. Ground Improvement, 11 (1), 3-10.

Croce, P. \& Modoni, G., 2007. Design of jet - grouting cut - off. Ground Improvement, 11 (1), 11-19.

de Rienzo, F., Oreste, P. \& Pelizza, S., 2008. Subsurface geological-geotechnical modelling to sustain underground civil planning. Engineering Geology, 96, 187-204. 
Fang, Y. S., Kao, C. C., Chou, J., Chain, K. F., Wang, D. R. \& Lin, C. T., 2006. Jet grouting with the superjet-midi method. Ground improvement, 10 (2), 69-76.

Flora, A., Lignola, G. P. \& Manfredi, G., 2007. A semi-probabilistic approach to the design of jet grouted umbrellas in tunnelling. Ground Improvement, 11 (4), 207-217.

Forth, R. A., 2004. Groundwater and geotechnical aspects of deep excavations in Hong Kong. Engineering Geology, 72, 253-260.

Hart, D. J., Bradbury, K. R. \& Feinstein, D. T., 2005. The vertical hydraulic conductivity of an aquitard at two spatial scales. Ground Water, 44 (2), 201-211.

Jurado-Elices, A., Pujades-Garnes, E., Vilarrasa, V., Vázquez-Suné, E. \& Carrera., J., 2009. Desarrollo de un método para resolver el drenaje de excavaciones entre pantallas. In Proceedings: Jornadas sobre el Agua y las Infraestructuras en el Medio Subterráneo, AIH-GE, Barcelona, 55-62.

Kimura, H.; Itoh, T.; Iwata, M. y Fujimoto, K., 2005. Application of new urban tunneling method in Baikoh tunnel excavation. Tunnelling and Underground Space Technology, 20, 151-158.

Knight, D. J., Smith, G. L. \& Sutton, J. S., 1996. Sizewell B foundation dewateringsystem design, construction and performance monitoring. Géotechnique, 46 (3), 473490.

Medina, A.; Carrera, J.; Alcolea, A. y Galarza, G., 2004. TRANSIN-IV Fortran code for solving the coupled non-linear flow and transport inverse problem. Hydrogeological Group, School of Civil Engineers, Technical University of Catalonia (Spain): 1-182.

Meier, P. M.; Carrera, J. \& Sánchez-Vila, X., 1998. An evaluation of Jacob's method for the interpretation of pumping tests in heterogeneous formations. Water Resources Research, 34 (5), 1011-1025. 
Mihalis, I. K., Tsiambaos, G. \& Anagnostopoulos, A., 2004. Jet grouting applications in soft rocks: the Athens Metro case. Geotechnical Engineering, 157, GE4, 219-228.

Modoni, G.; Croce, P. \& Mongiovi, L., 2006. Theoretical modelling of jet grouting. Géotechnique, 56 (5), 335-347.

Papadopulos, I. S. \& Cooper, H. H. J., 1967. Drawdown in a well of large diameter. Water Resources Research, 3 (1), 241-244.

Pichler, C., Lackner, R., Spira, Y. \& Mang, H. A., 2003. Thermochemomechanical assessment of ground improvement by jet grouting in tunneling. Journal of Engineering Mechanism, 129 (8), 951-962.

Pickles, A. R., Lee, S. W. \& Norcliffe, B. A. W., 2003. Groundwater and ground movement around deep excavation. Geotechnical Engineering, 156 (GE3), 147-58.

Rowson, J., 2009. Cologne: groundwater extraction method probed, New Civil Engineer, http://www.nce.co.uk/print-magazine/cologne-groundwater-extractionmethod-probed/1995535.article

Shaqour, F. M. \& Hasan, S. E., 2008. Groundwater control for construction purposes: a case study from Kuwait. Environmental Geology, 53, 1603-1612.

Tatiya, R. (ed), 2005. Civil excavations and tunneling: a practical guide. Thomas Telford, London.

Thiem, G. (ed), 1906. Hydrologische Methode. Leipzig, Gebhardt.

Thierry, P., Prunier-Leparmentier, A.-M., Lembezat, C., Vanoudheusden, E. \& Vernoux, J.-F., 2009. 3D geological modelling at urban scale and mapping of ground movement susceptibility from gypsum dissolution: The Paris example (France). Engineering Geology, 105, 51-64.

Trinchero, P., Sanchez-Vila, X., Copty, N. \& Findikakis, A., 2008. A new method for the interpretation of pumping tests in leaky aquifers. Ground Water, 46 (1), 133-143. 
Vilarrasa, V., Jurado-Elices, A., Vázquez-Suñé, E., Carrera, J. \& Pujades-Garnés, E., 2009. La modelación: un elemento clave en el seguimiento hidrogeológico de las obras de la LAV - tramo La Torrassa - Sants. In Proceedings: Jornadas sobre el Agua y las Infraestructuras en el Medio Subterráneo, AIH-GE, Barcelona, 235-242.

Wheatcraft, S. W. \& Winterberg, F., 1985. Steady state flow passing through a cylinder of permeability different from the surrounding medium. Water Resources Research, 21 (12), 1923-1929.

Xu, Y.-S., Shen, S.-L. \& Du, Y.-J., 2009. Geological and hydrogeological environment in Shangai with geohazards to construction and maintenance of infrastructures. Engineering Geology, doi: 10.1016/j.enggeo.2009.08.009. 


\section{FIGURES}

Figure 1: Location of the civil works, the Spanish High Speed Train and the Barcelona metro line L-9, placed South of Barcelona in the Llobregat Delta.

Figure 2: Geometry of the problem, in which a flow rate $Q$ is pumped in the centre of an annular low-permeability barrier (shadowed area), with inner radius $R$, thickness $e$, transmissivity $T^{\prime}$ and storage coefficient $S^{\prime}$, and aquifer transmissivity $T$ and aquifer storage coefficient $S$ for (a) a closed ring, (b) a ring with an angular aperture $\theta$ with three orientations (O1, $\mathrm{O} 2$ and $\mathrm{O} 3)$, and (c) a vertical cross section showing the drawdown, $s$, and the change of head in the lowpermeability barrier, $\Delta h_{b}$.

Figure 3: Dimensionless drawdown versus time in (a) semilog and (b) log-log scales, at a dimensionless distance of 0.9 from the pumping well (inside the excavation zone), in response to a constant pumping rate. Results are presented for several values of the dimensionless head drop across the low-permeability barrier $\gamma=T e /\left(T^{\prime} R\right)$ without aperture. The phases correspond to (a) $\gamma=20$ and (b) $\gamma=2 \cdot 10^{3}$

Figure 4: Dimensionless drawdown versus time in (a) semilog and (b) $\log$-log scales, at a dimensionless distance of 1.25 from the pumping well (outside the excavation zone), in response to a constant pumping rate. Results are presented for several values of the dimensionless head drop across the low-permeability barrier $\gamma=T e /\left(T^{\prime} R\right)$ without aperture. The phases correspond to $\gamma=2 \cdot 10^{3}$.

Figure 5: (a) Dimensionless drawdown when pumping in the center of the lowpermeability barrier, which presents an aperture in Orientation 1. A pumping cone is formed outside the low-permeability barrier and a dome inside it around 
the aperture. (b) Cross-section showing the dimensionless drawdown versus distance for the three orientations compared to the case without aperture.

Figure 6: Dimensionless drawdown versus time in (a) semilog and (b) log-log scales, at a dimensionless distance of 1.25 from the pumping well (outside the excavation zone), in response to a constant pumping rate. Results are presented for several apertures and orientations for a $\gamma=2 \cdot 10^{3}$.

Figure 7: Dimensionless pumping rate versus time in (a) semilog and (b) log-log scales, with a constant head in the pumping well. Results are presented for several values of the dimensionless head drop across the low-permeability barrier $\gamma=T e /\left(T^{\prime} R\right)$ without aperture.

Figure 8: Dimensionless drawdown versus time in (a) semilog and (b) log-log scales, at a dimensionless distance of 1.25 from the pumping well (outside the excavation zone), when fixing the head in the pumping well. Results are presented for several apertures and orientations for a $\gamma=2 \cdot 10^{3}$.

Figure 9: Dimensionless pumping flow rate as a function of the aperture for several dimensionless times for a $\gamma=2 \cdot 10^{3}$.

Figure 10: (a) Cross section of the High Speed Train in its arrival to Barcelona, showing the geology, the tunnel and the jet-grouting treatment, and (b) a plan view of the jet-grouting treatment.

Figure 11: Outline of the geometry and geology, with the hydraulic properties of each layer, of the metro station of the L-9 Foc Cisell.

Figure 12: (a) Plan view of the Plaça Catalunya L-9 metro station, showing the geometry of the low-permeability barrier and the position of the piezometers and (b) a cross section showing the geology and geometry. 
Figure 13: Dimensionless drawdown versus time in log-log scale for an observation point outside the low-permeability barrier at the Foc Cisell L-9 station, where a constant flow rate is pumped.

Figure 14: Dimensionless drawdown versus time in log-log scale for several observation points outside the low-permeability barrier at the Plaça Catalunya L-9 station, with a constant hydraulic head inside the enclosure.

Figure 15: Dimensionless flow rate versus time at the Plaça Catalunya L-9 station for a constant hydraulic head inside the enclosure. 


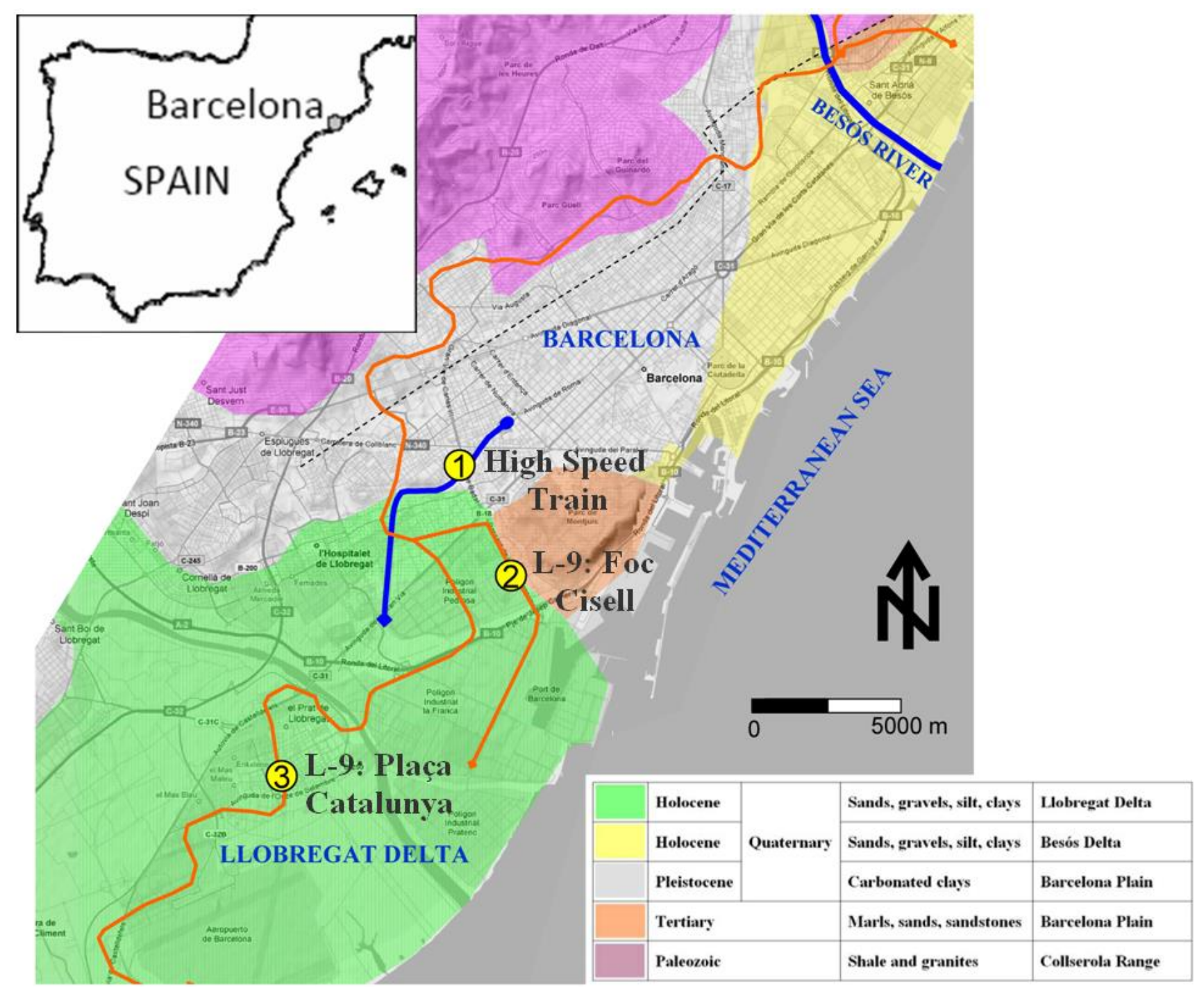

Figure 1 
a)

b)

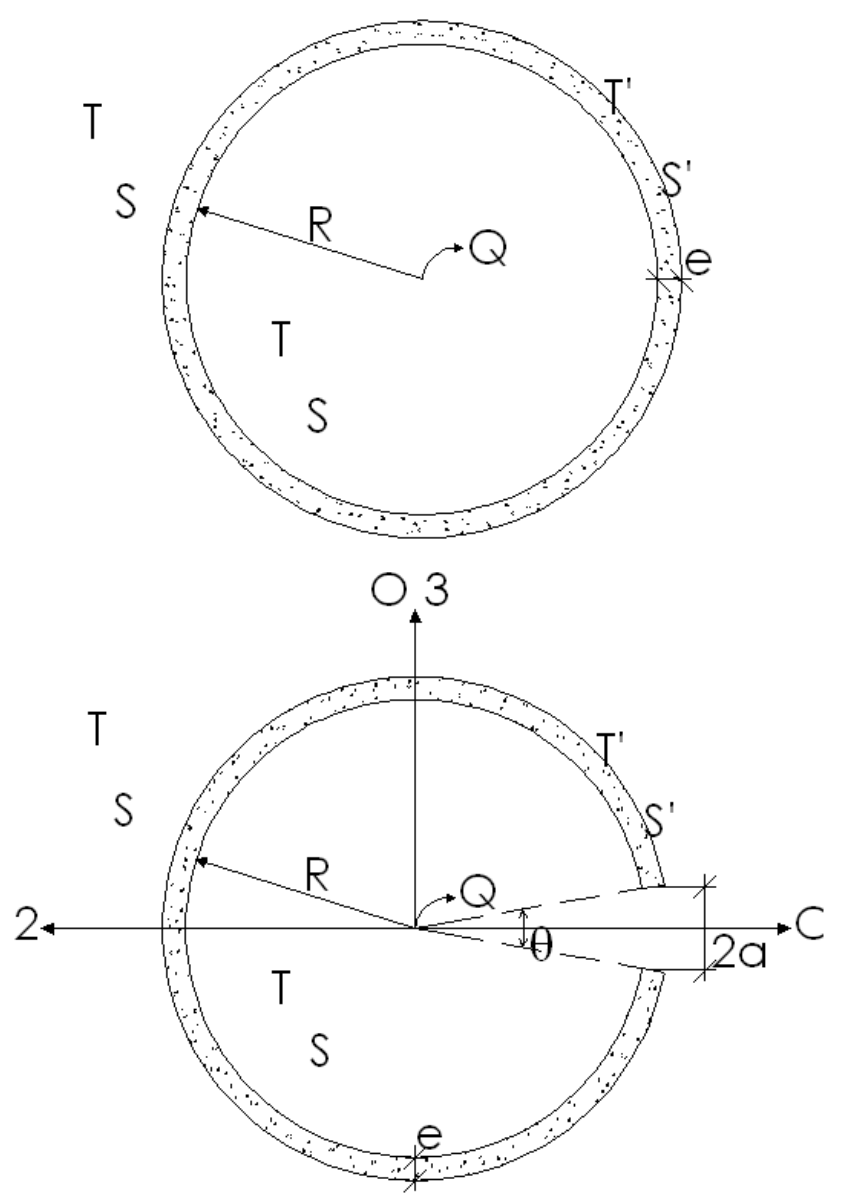

Excavation

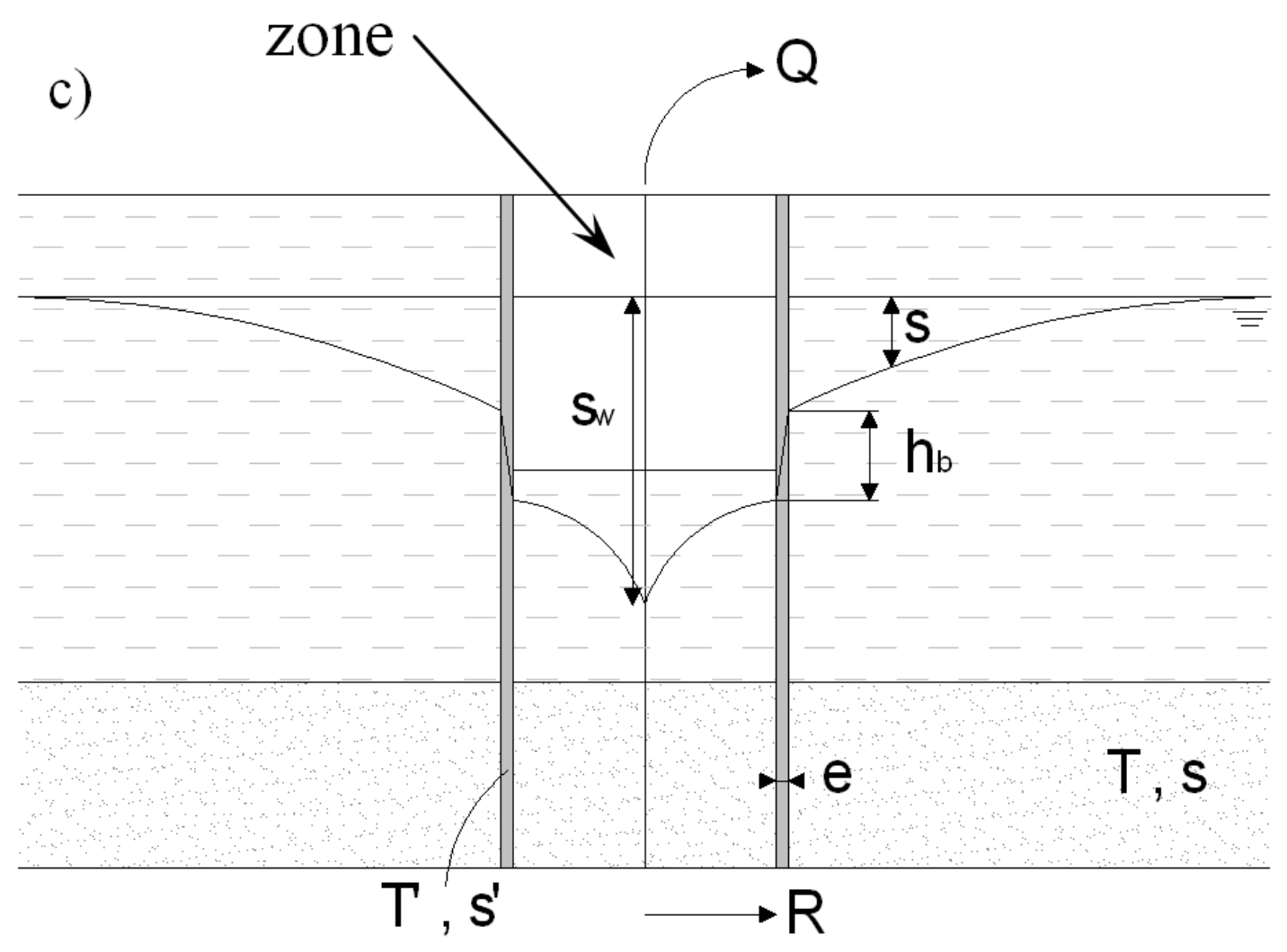

Figure 2 


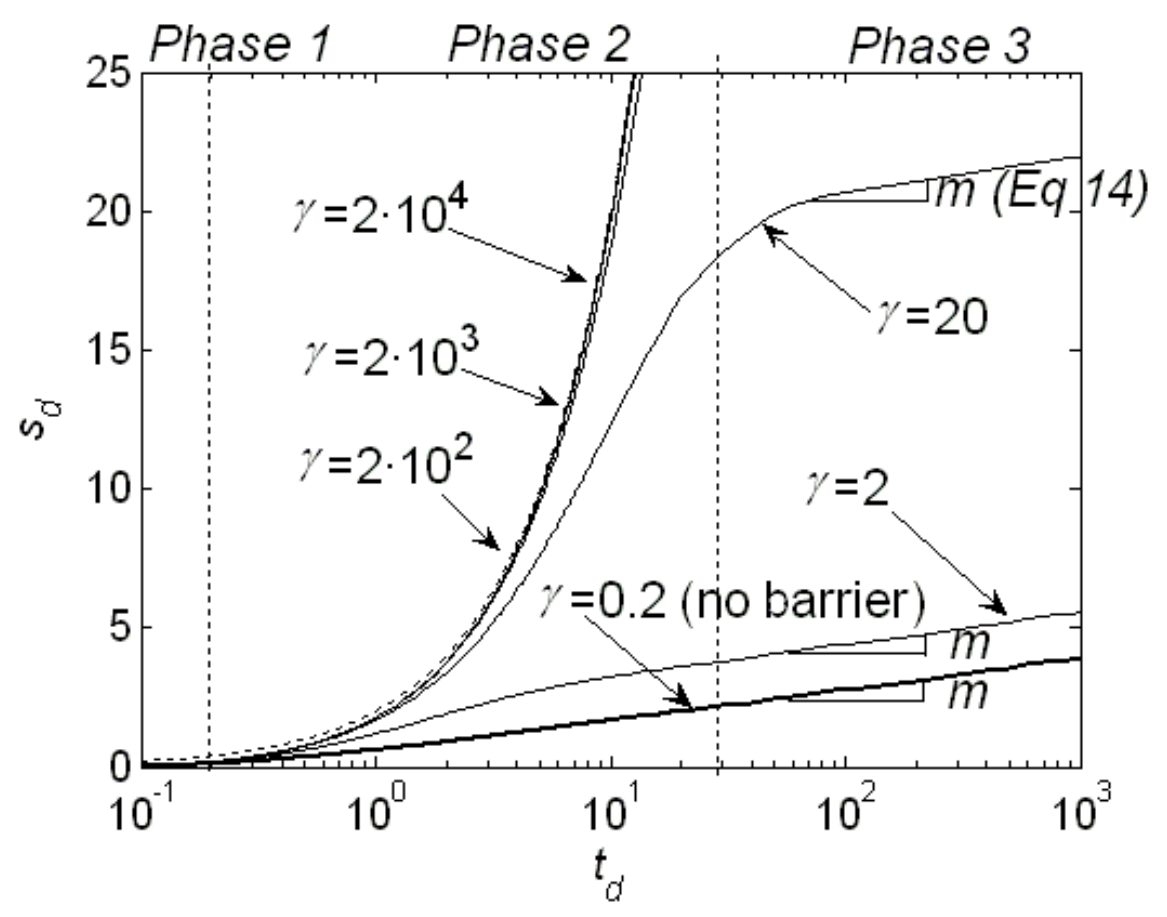




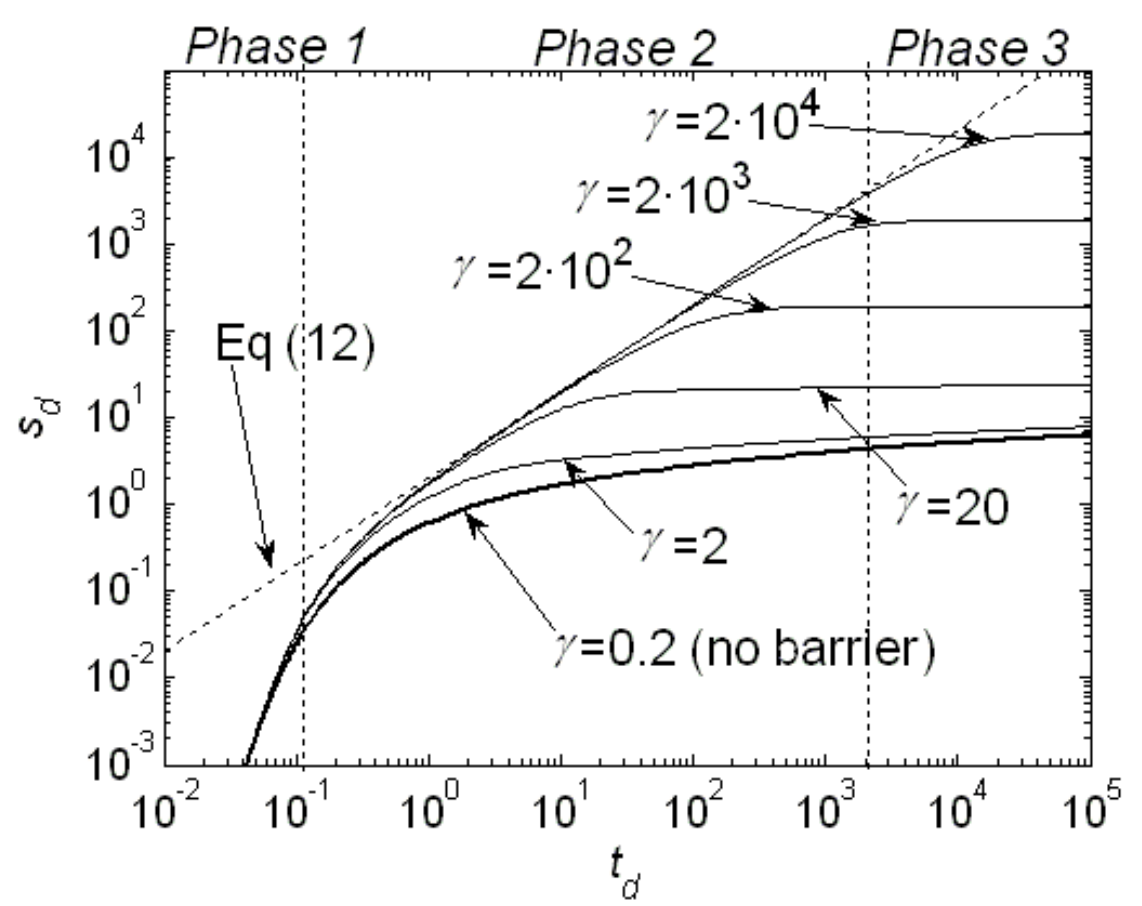

Figure 3 


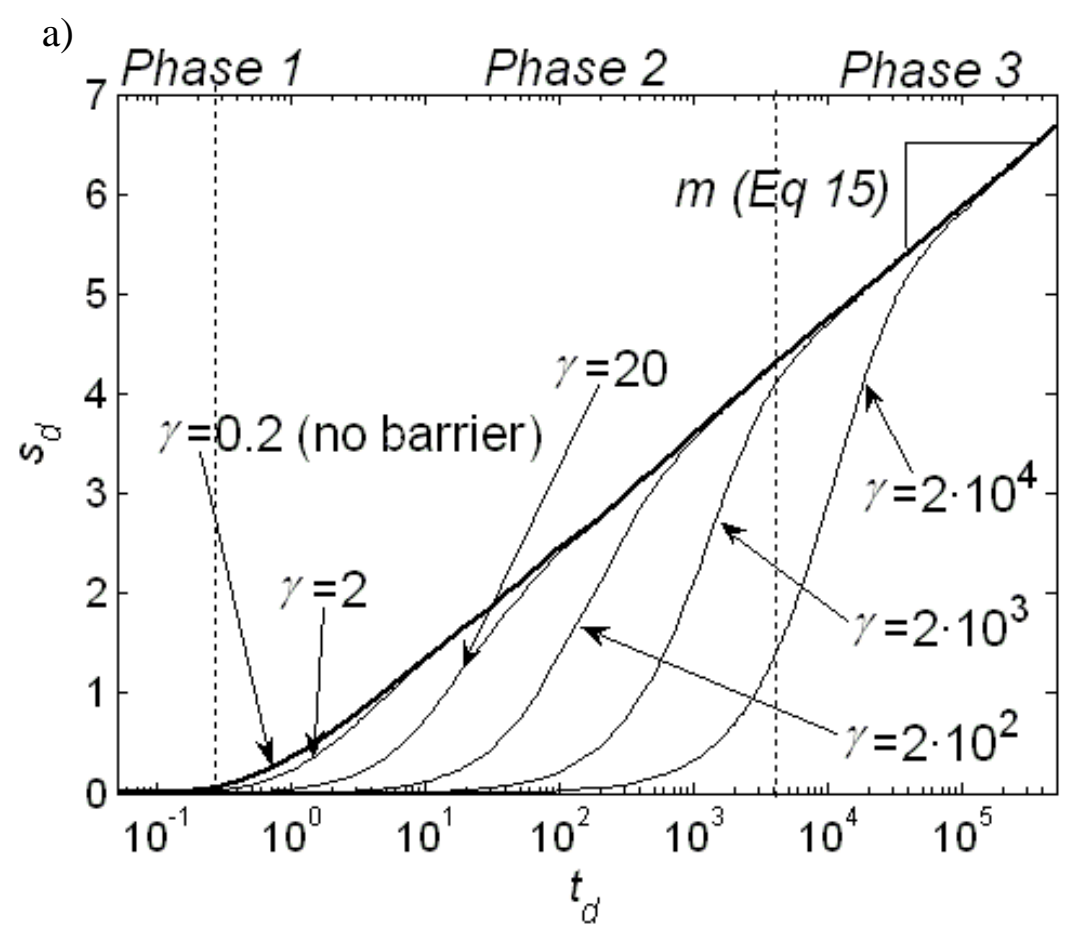

b) 


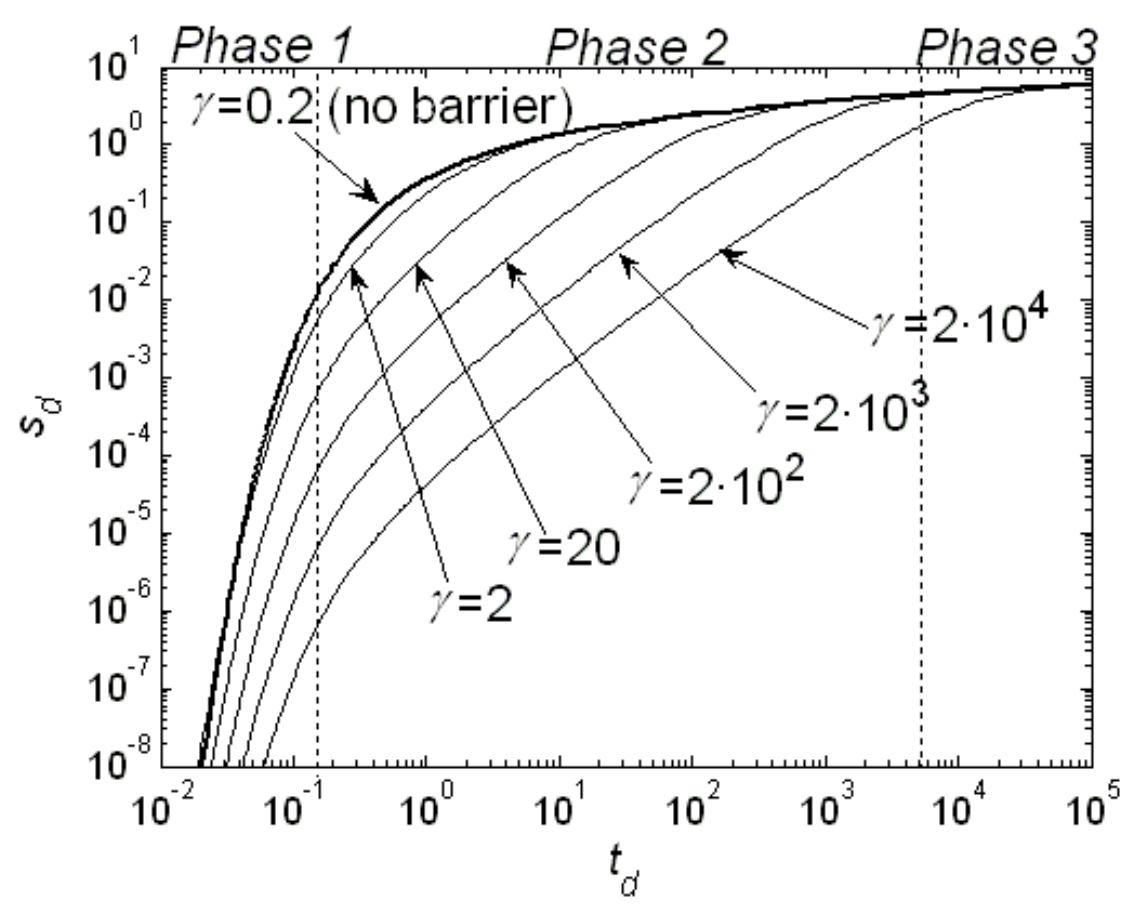

Figure 4 


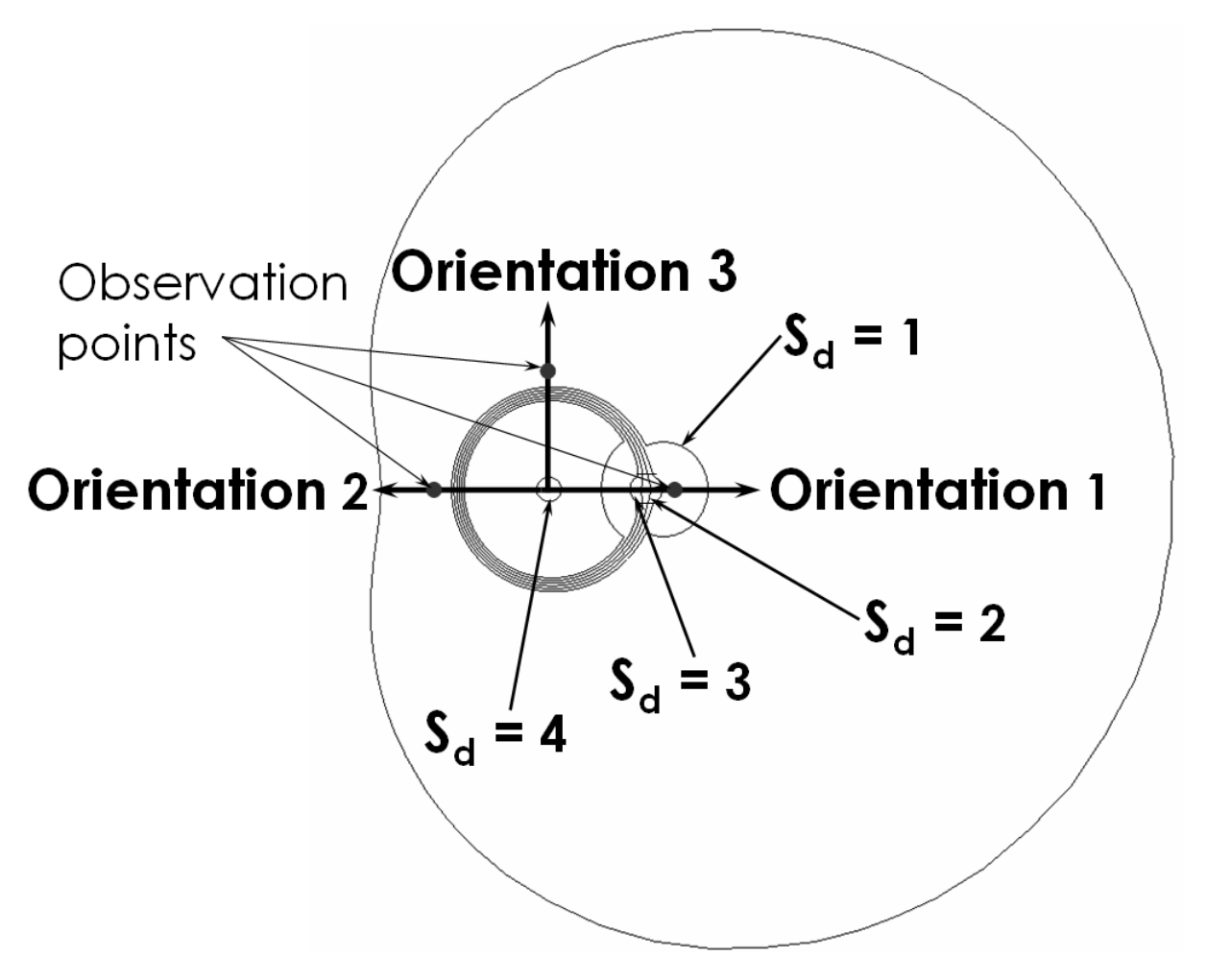


a)

b)

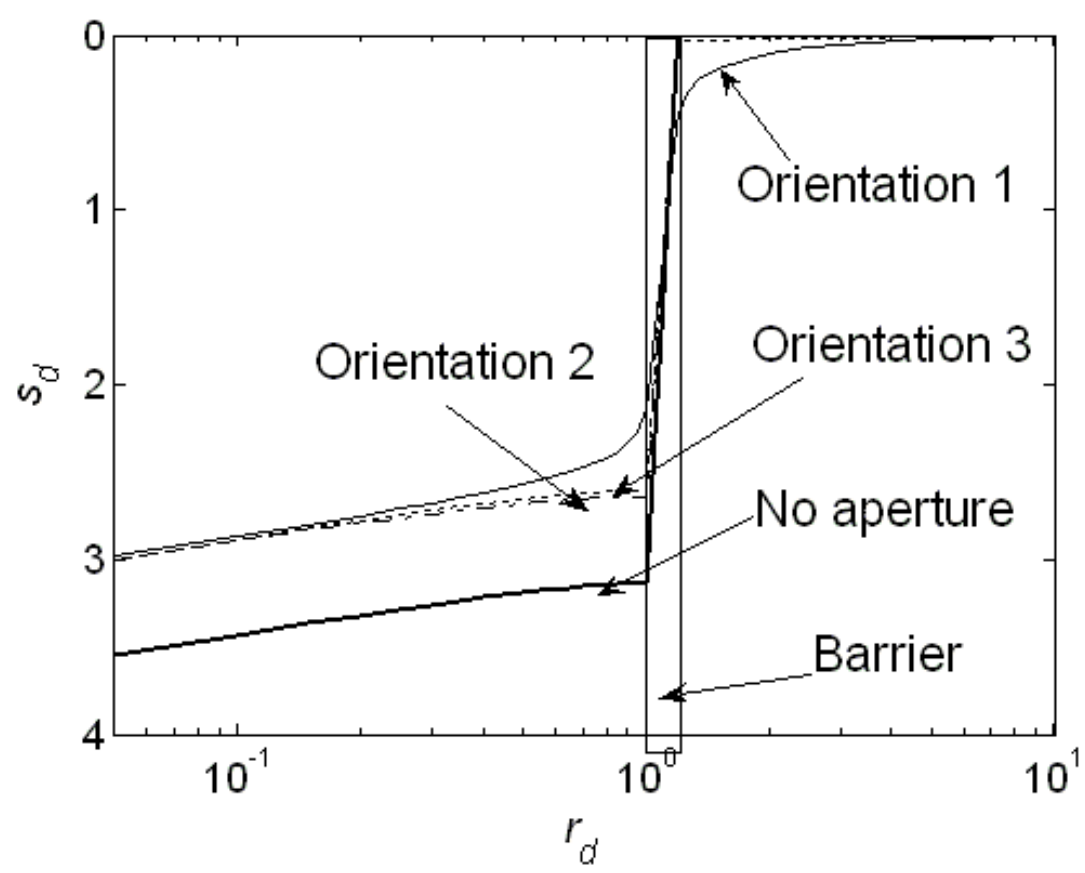

Figure 5 


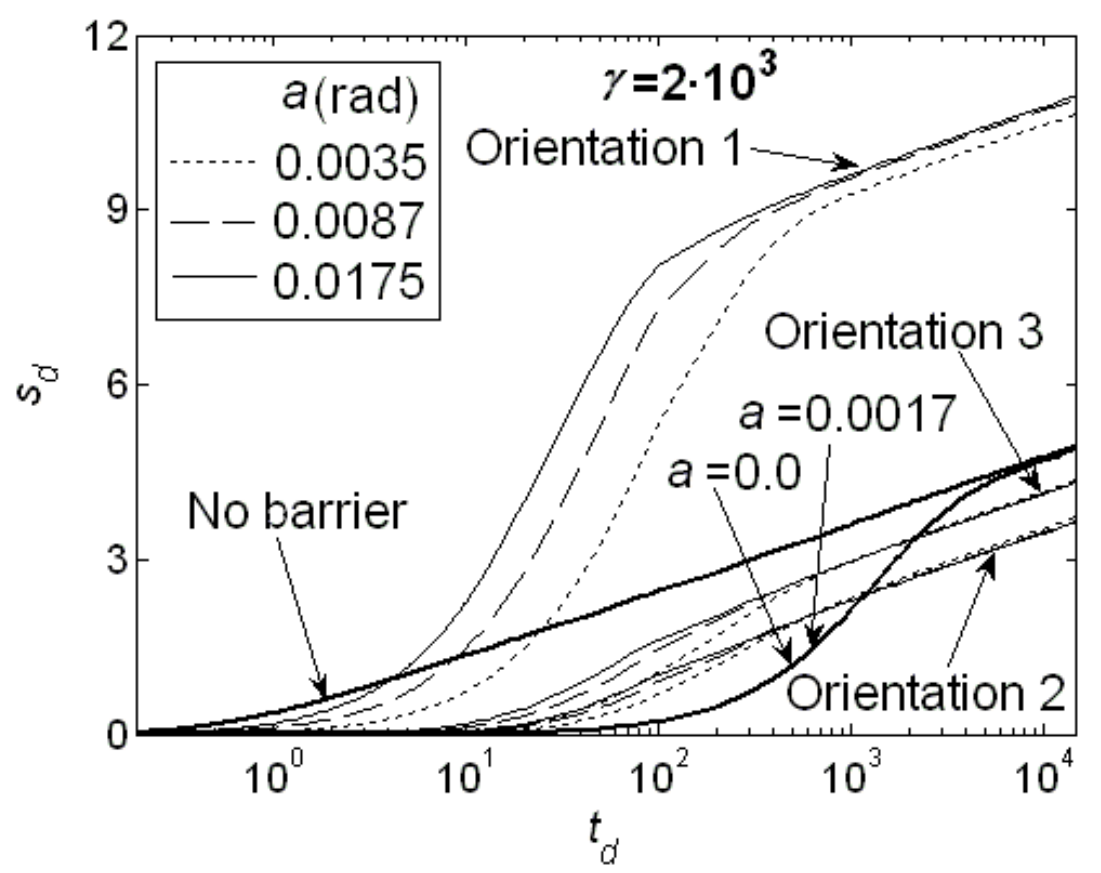




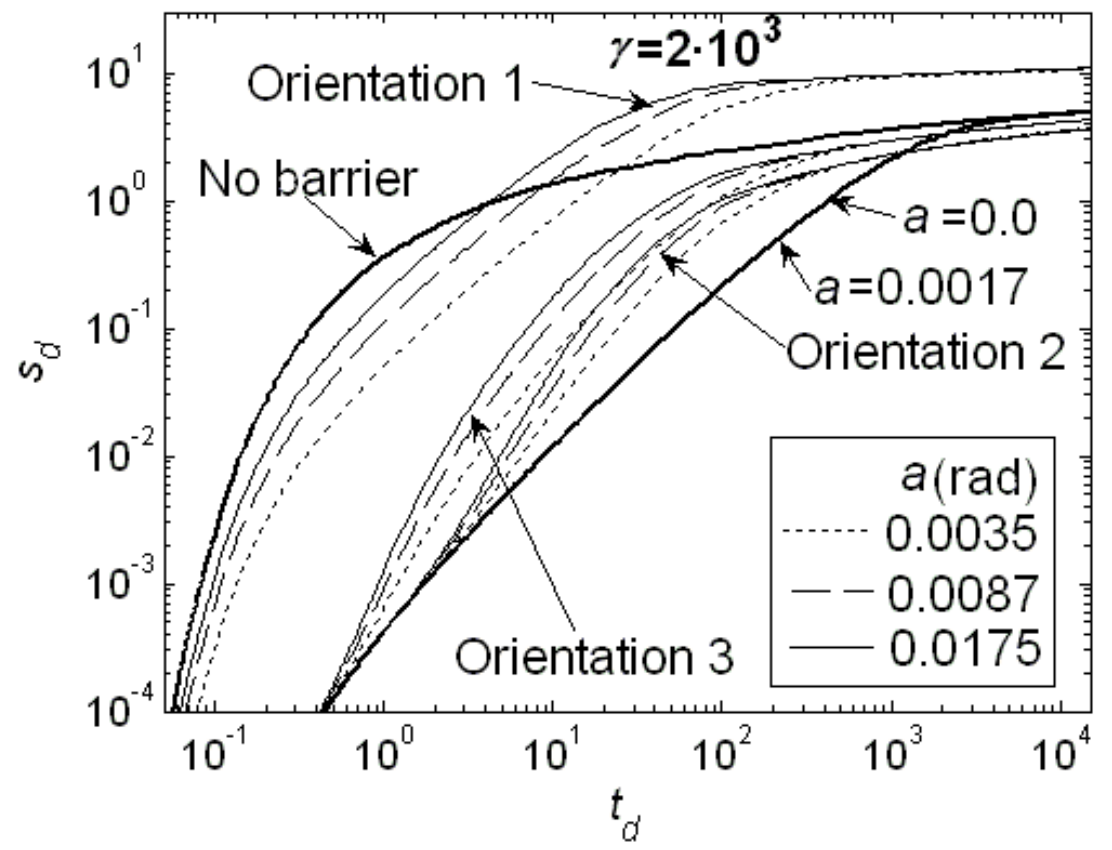

Figure 6 
a)

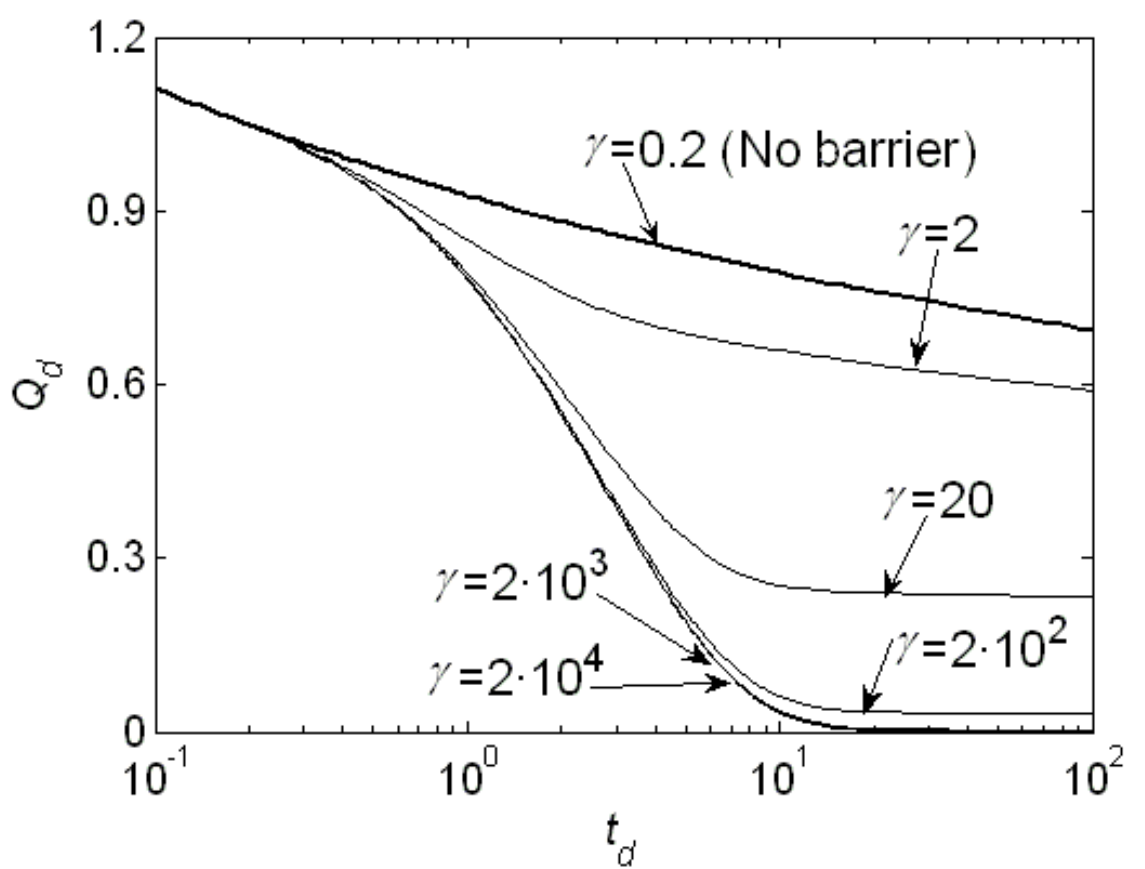

b) 


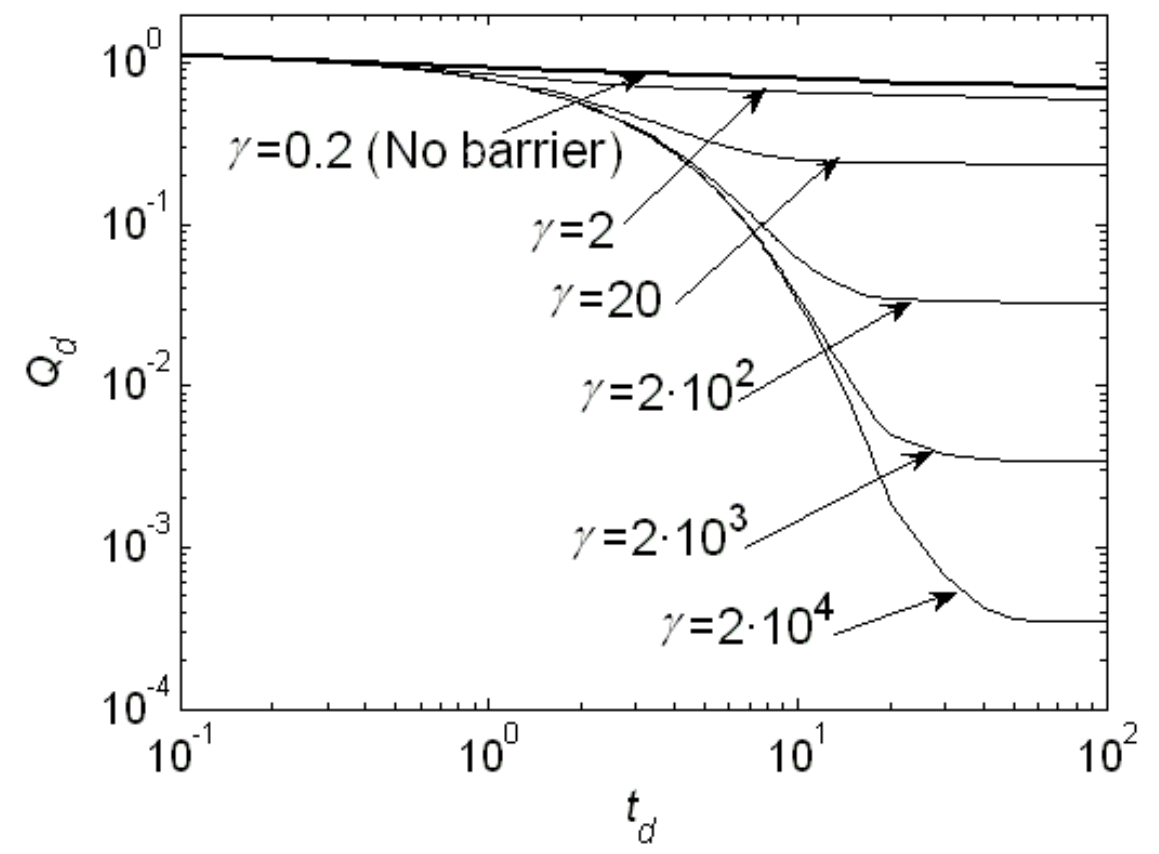

Figure 7 


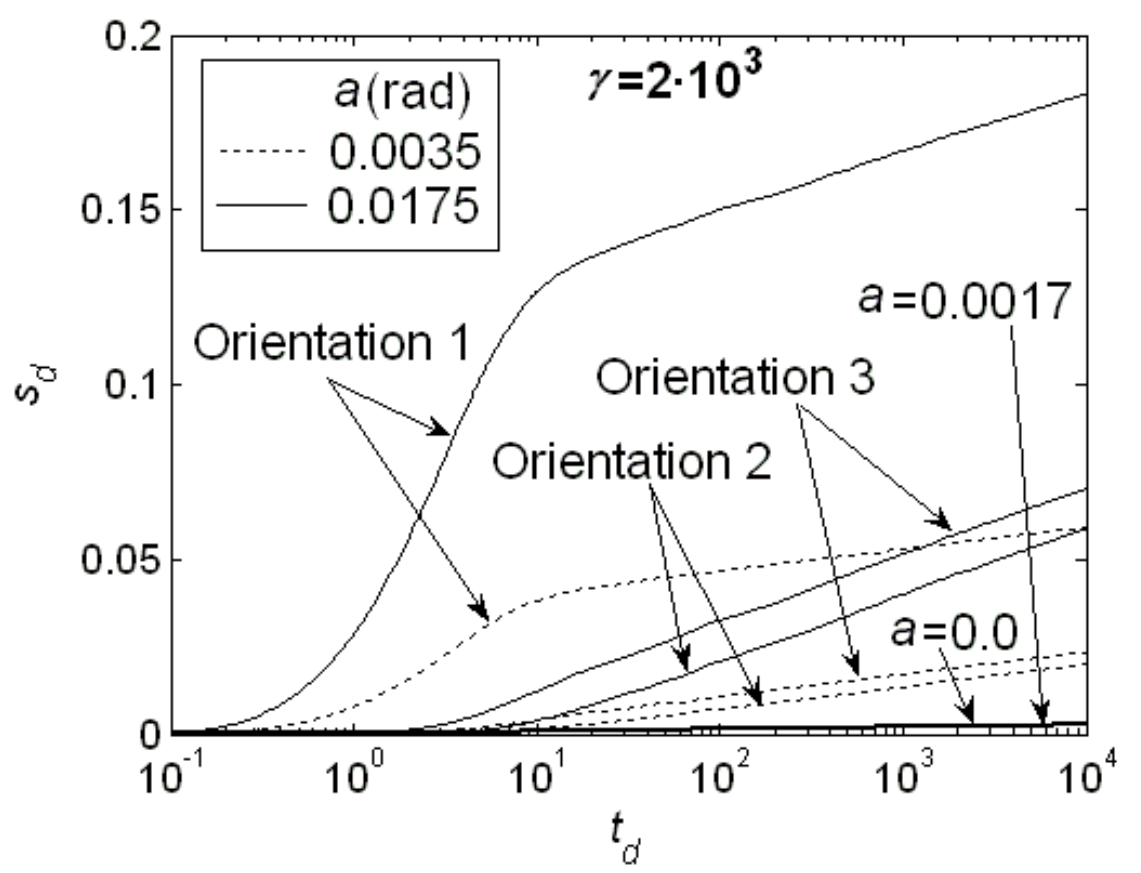




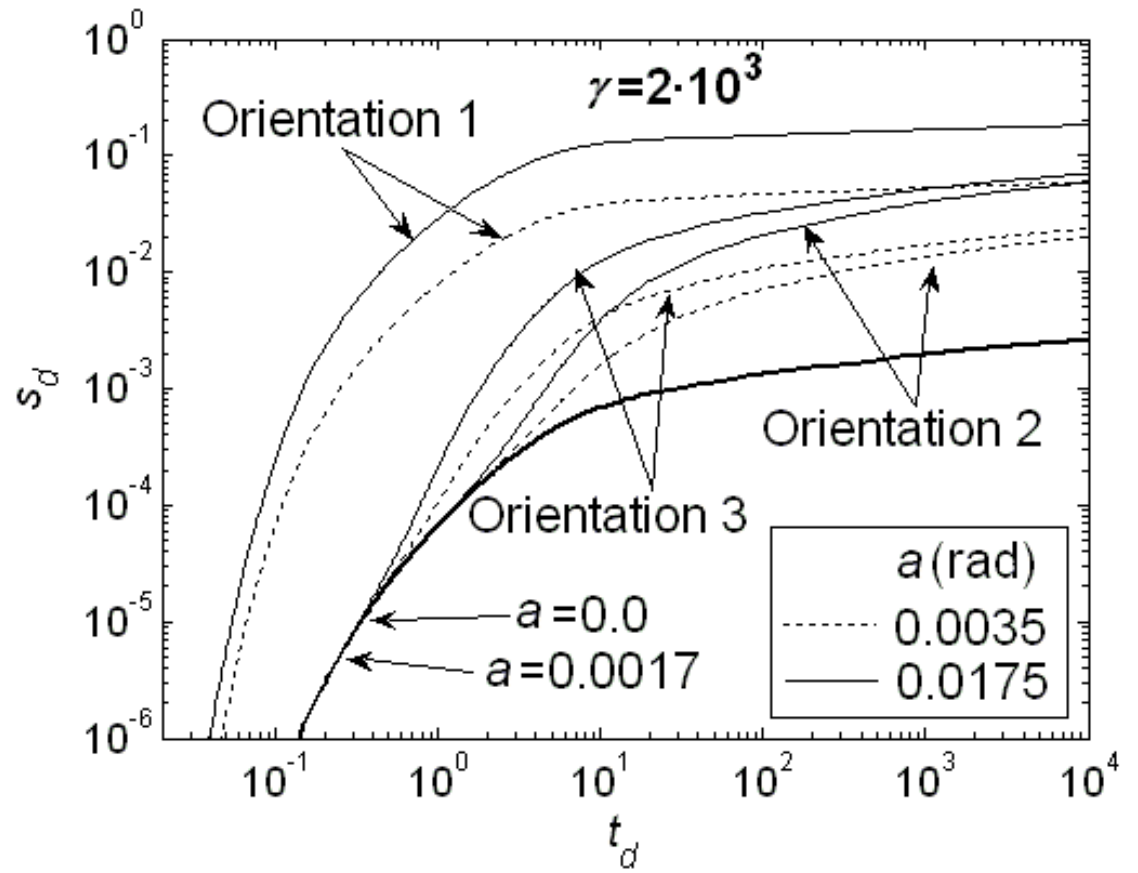

Figure 8 


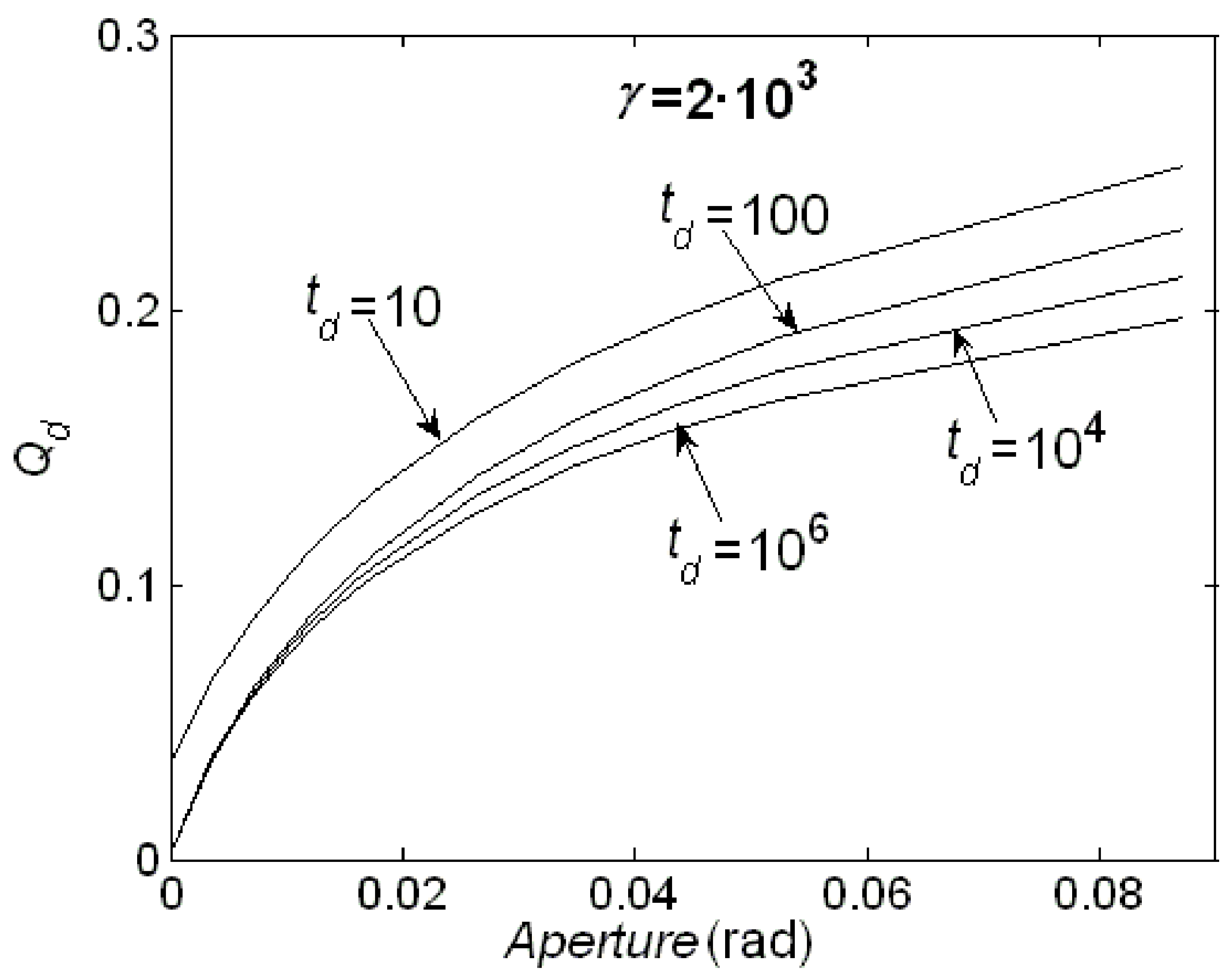

Figure 9 


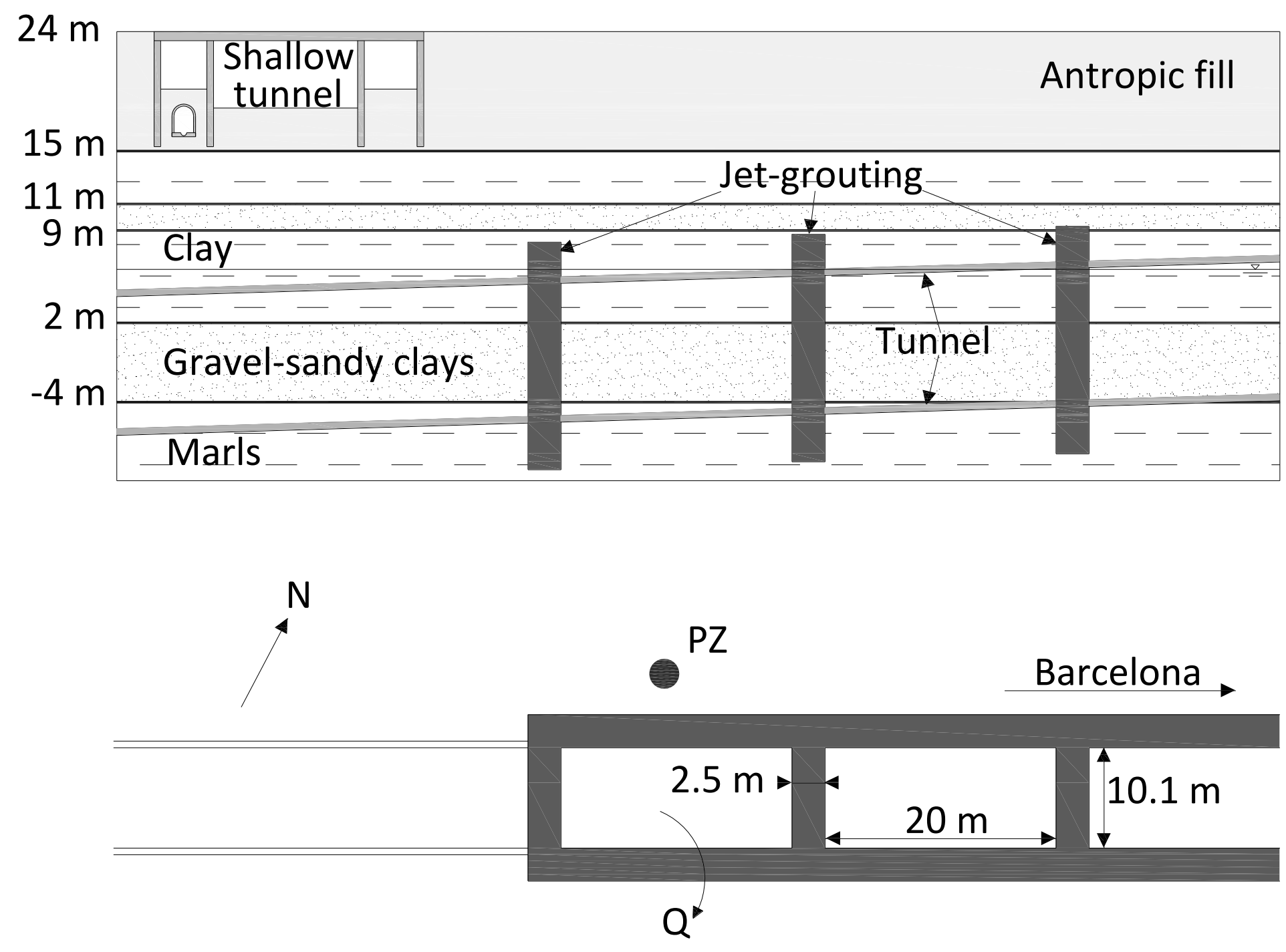

Figure 10 


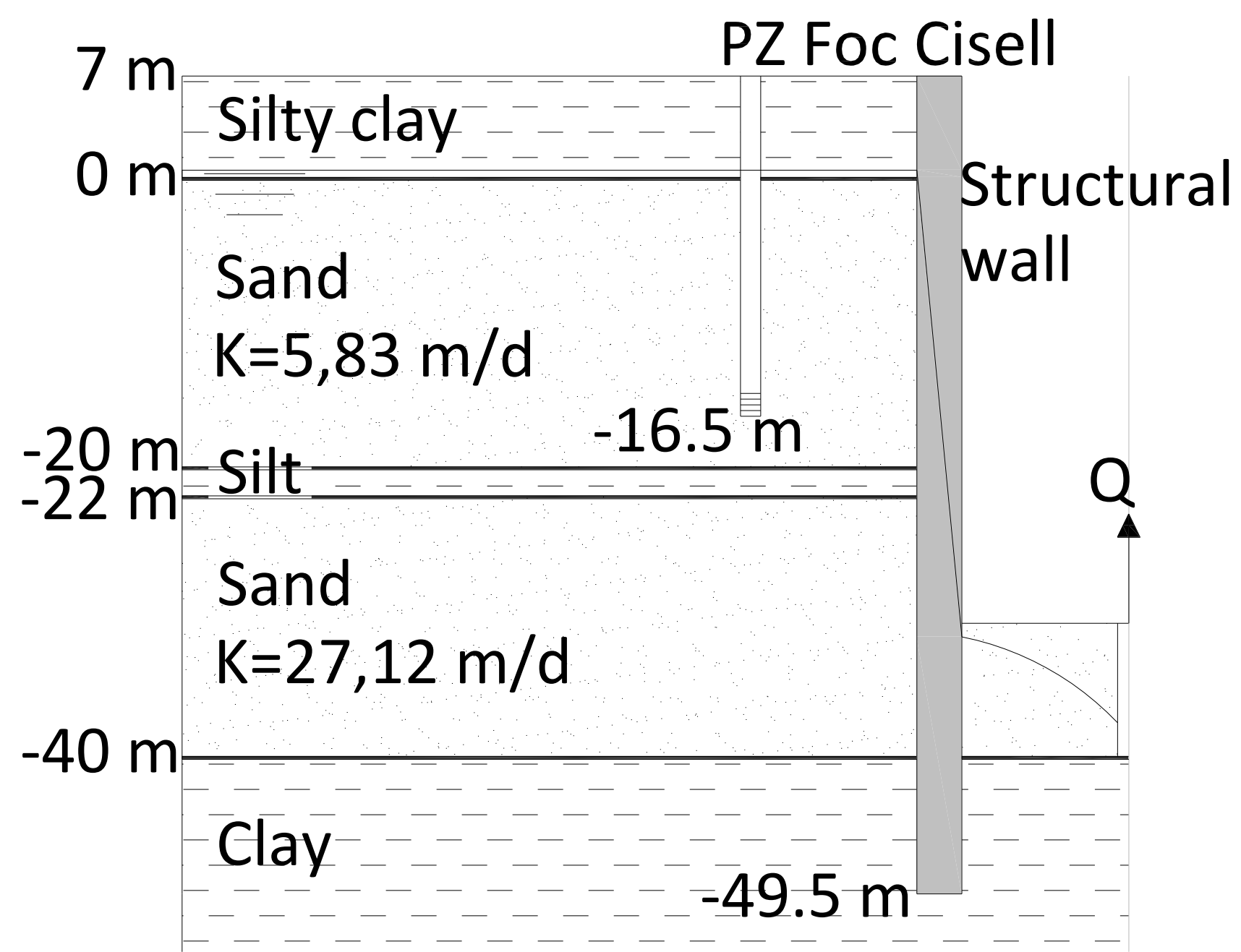

Figure 11 
(a)

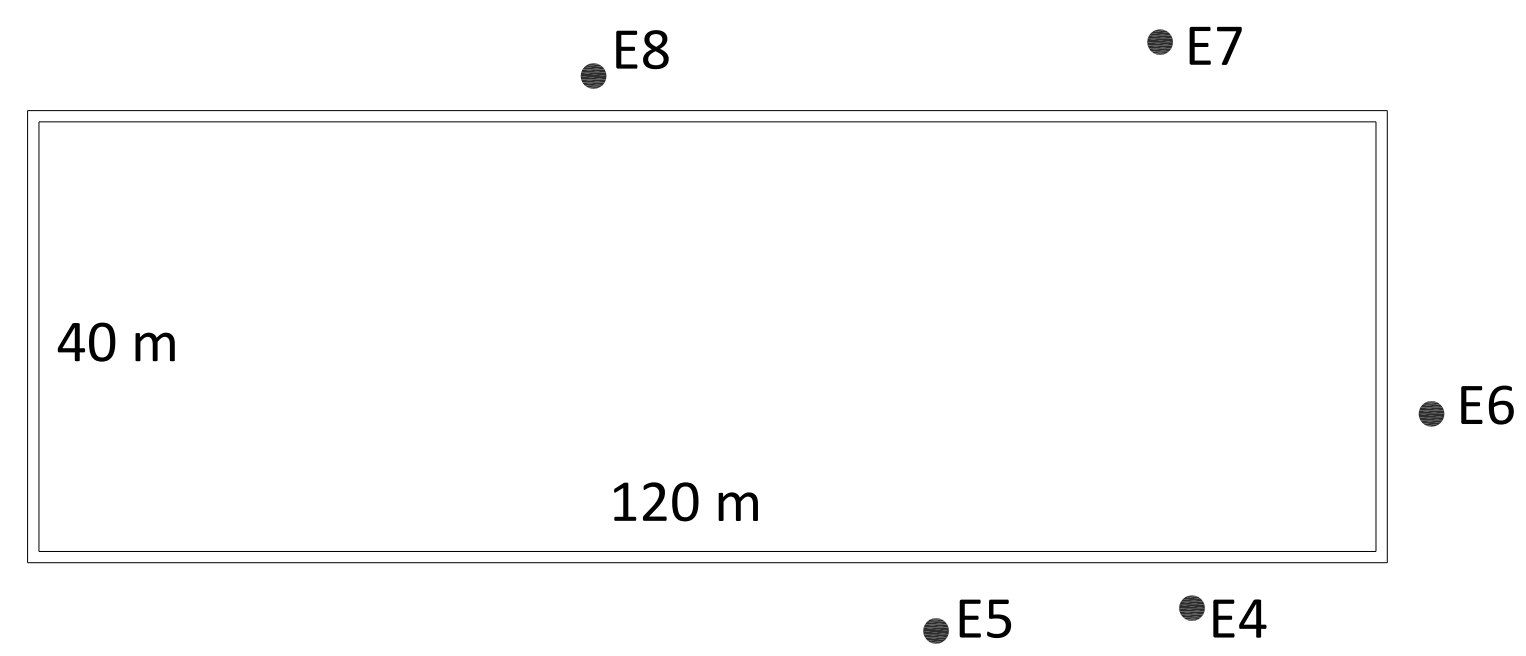

(b)

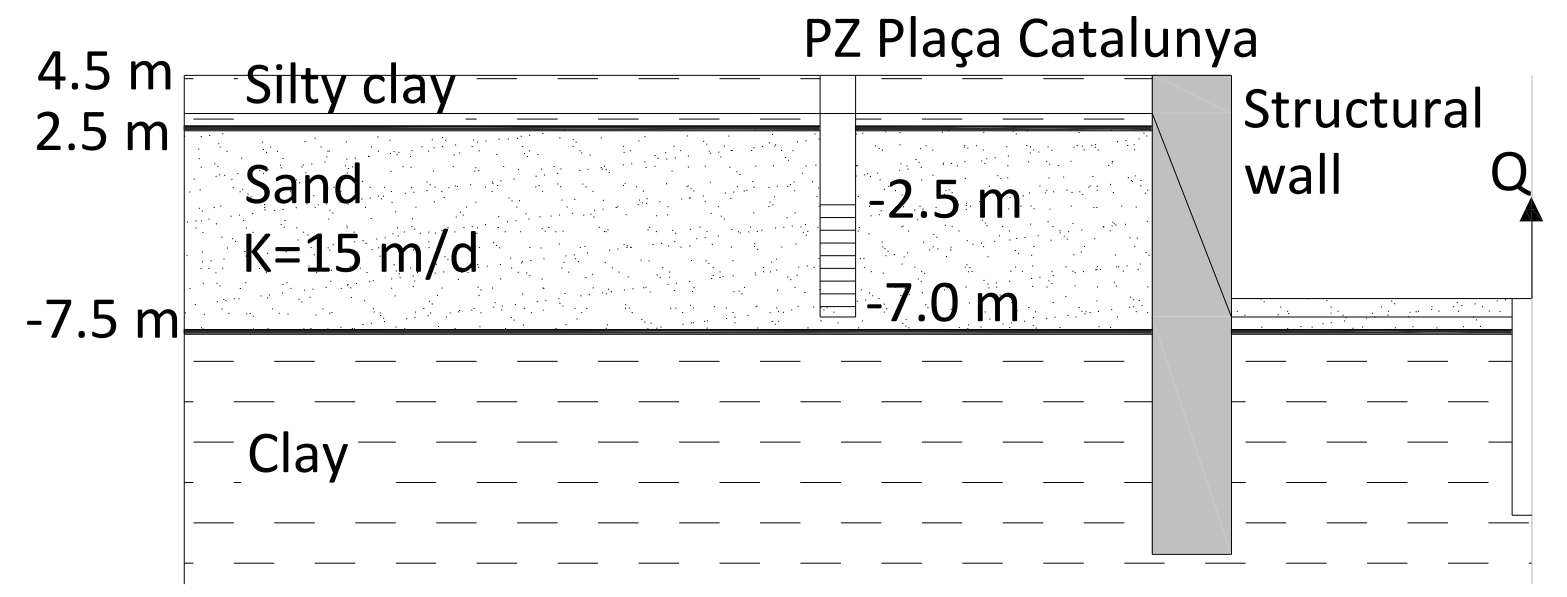

Figure 12 


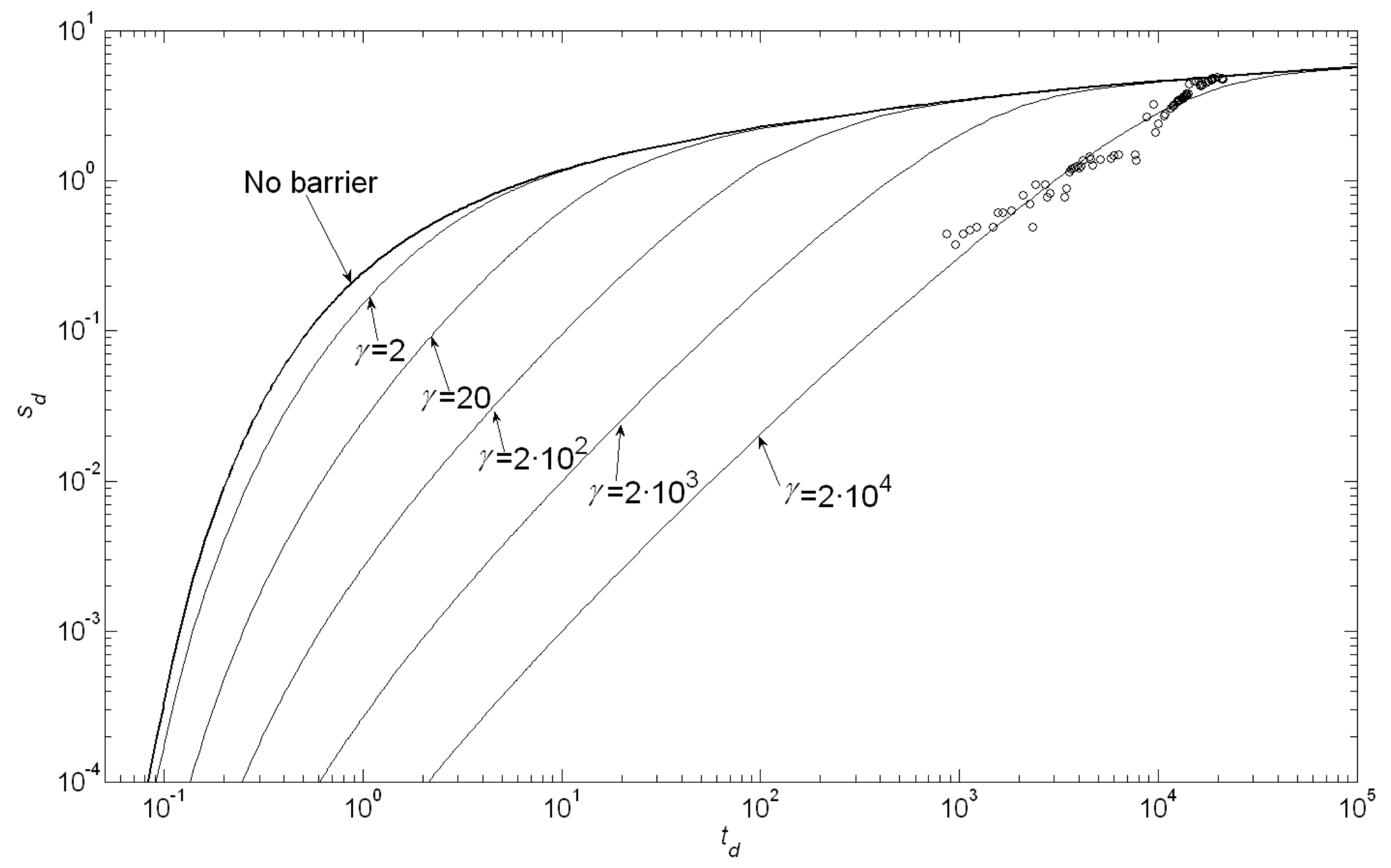

Figure 13 


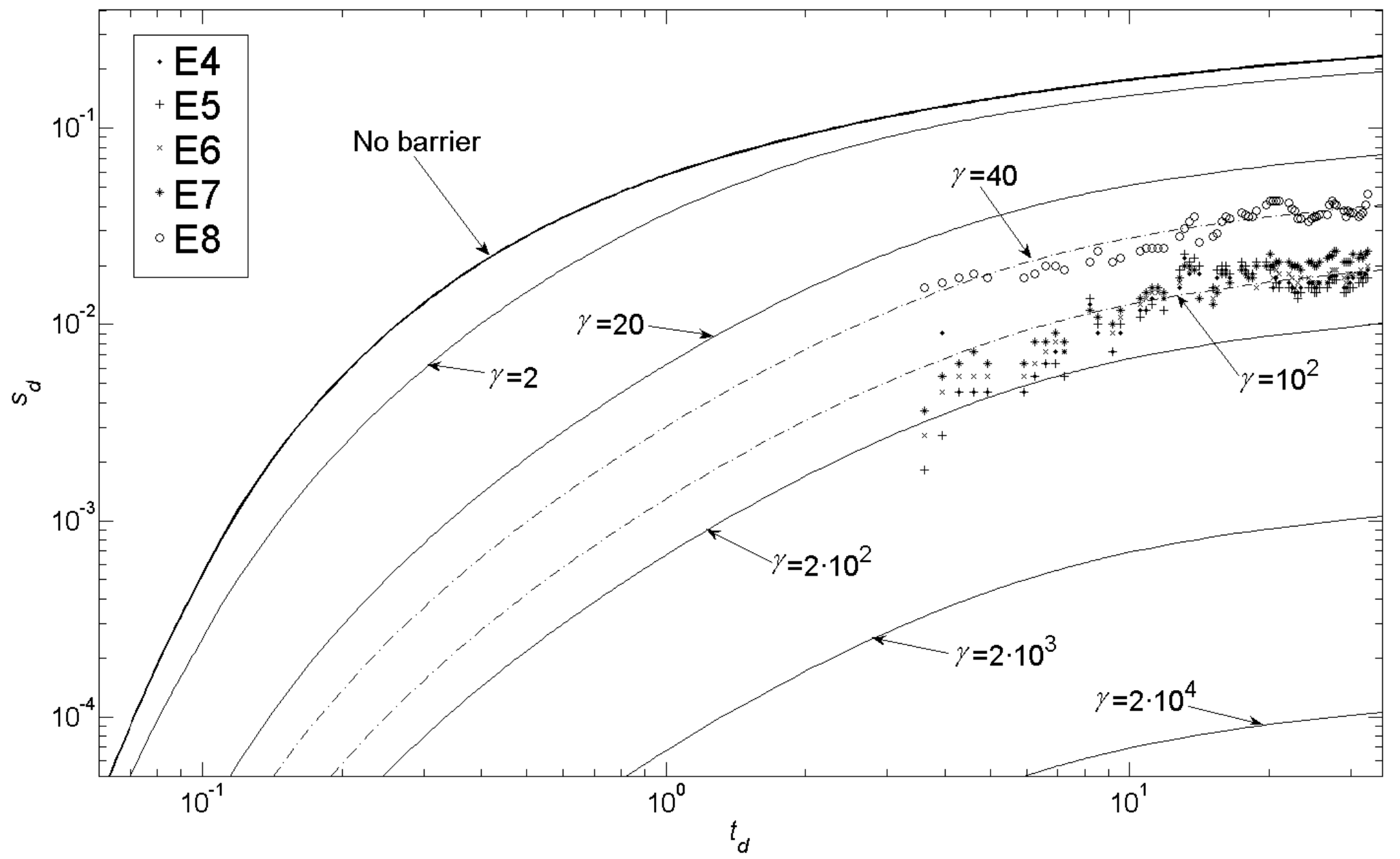

Figure 14 


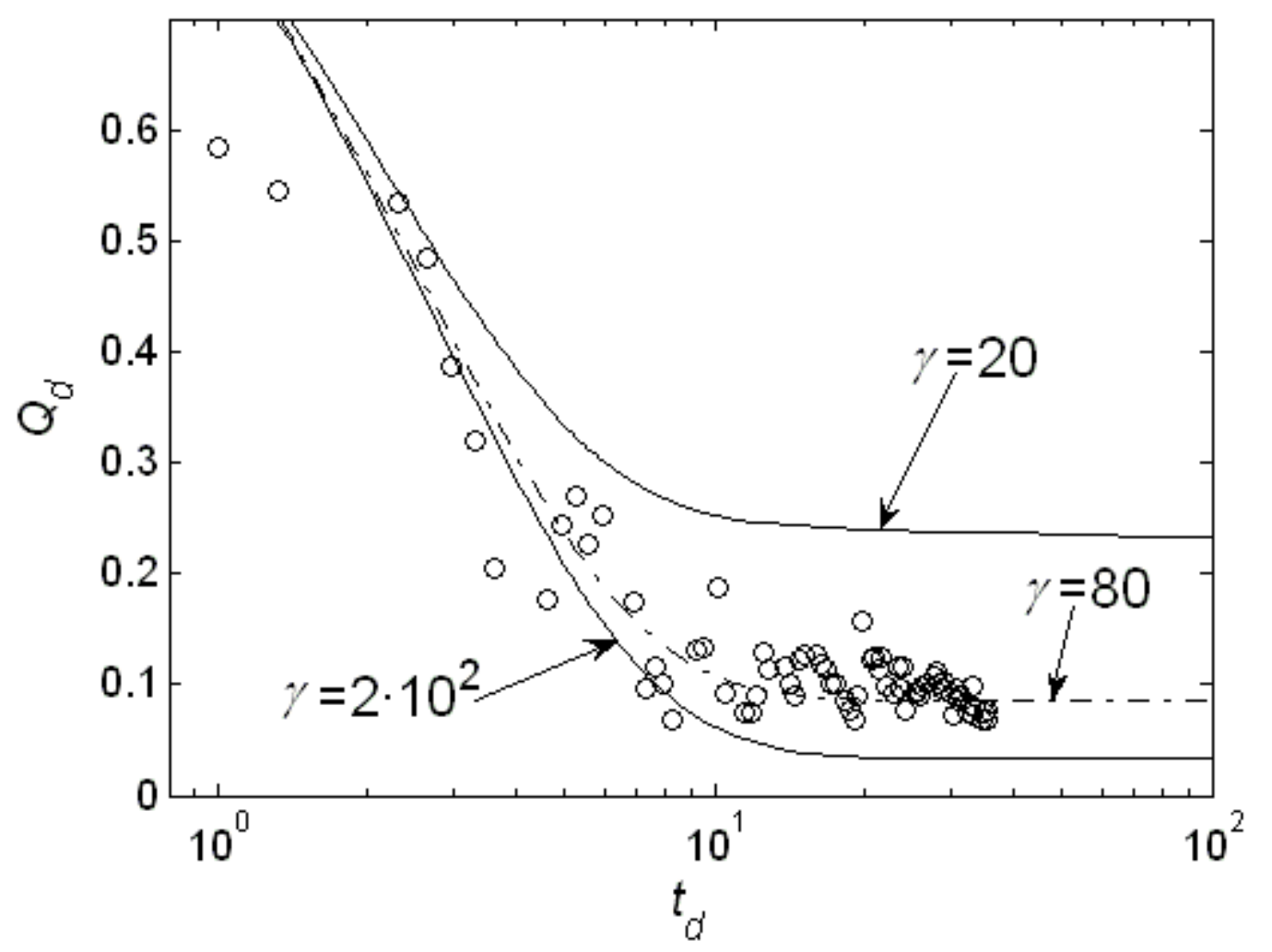

Figure 15 


\section{APPENDIX A}

Applying the Thiem (1906) solution for drawdown in the low-permeability barrier yields a head drop across the barrier equal to

$$
\Delta h_{b}=\frac{Q}{2 \pi T^{\prime}} \ln \left(\frac{R+e}{R}\right) \text {. }
$$

Equation (A.1) can be expressed in dimensionless form as

$$
\Delta h_{b_{D}}=\frac{T}{T^{\prime}} \ln \left(1+\frac{e}{R}\right) .
$$

Recalling the following property of the logarithm when $x$ is small

$$
\ln (1+x) \approx x
$$

And assuming that $e / R$ is small, equation (A.2) gives equation (7).

\section{APPENDIX B}

When solving the flux equation by means of numerical methods, a certain error is introduced due to spatial discretization of the media. This appendix shows the effect of the mesh discretization in the pumping well and its apparent radius, which gives the same drawdown as the given by the numerical simulation, is calculated. Figure B.1 shows an isosceles triangular element that forms the well (node 1), where a flow rate $Q$ is pumped.

The flux equation is solved using the finite elements method

$$
\mathbf{T} \cdot \mathbf{h}=\mathbf{b}
$$

where

$$
T_{i j}=\int_{V} \nabla N_{i} \mathbf{K} \nabla N_{j} d V
$$

and

$$
b_{i}=\int_{\partial V_{n}} N_{i} q_{n} \mathrm{~d} A_{n}+\int_{V} N_{i} r \mathrm{~d} V
$$


where $\mathbf{T}$ and $\mathbf{K}$ is the transmissivity and hydraulic conductivity tensors respectively, $\mathbf{h}$ is the head vector, which is unknown, $\mathbf{b}$ is the independent term, $N$ are the shape functions, $V$ is volume, $A_{n}$ is area, $q_{n}$ is flux perpendicular to the surface and $r$ is a source/sink term. The suffixes $i$ and $j$ refers to the nodes that form the triangular element.

The shape functions for each node are calculated as

$$
N_{i}(x, y)=\frac{1}{2 A^{e}}\left(a_{i}+b_{i} x+c_{i} y\right)
$$

where,

$$
\begin{gathered}
a_{i}=x_{j} y_{k}-x_{k} y_{j}, \\
b_{i}=y_{j}-y_{k}, \\
c_{i}=x_{k}-x_{i},
\end{gathered}
$$

where $i, j$ and $k$ refer to the nodes of the triangular element ordered in counter-clockwise direction, and

$$
A^{e}=\frac{1}{2} 2 R_{e} \sin \alpha R_{e} \cos \alpha=R_{e}^{2} \sin \alpha \cos \alpha=\frac{R_{e}^{2}}{2} \sin 2 \alpha,
$$

where $A^{e}$ is the area of the triangle, $R_{e}$ is the size of the element and $\alpha=\pi / n$.

Calculating the shape functions in the nodes gives

$$
\begin{gathered}
N_{1}(x, y)=1-\frac{x}{R_{e} \cos \alpha}, \\
N_{2}(x, y)=\frac{x \sin \alpha-y \cos \alpha}{R_{e} \sin 2 \alpha}, \\
N_{3}(x, y)=\frac{x \sin \alpha+y \cos \alpha}{R_{e} \sin 2 \alpha} .
\end{gathered}
$$

The elements of the transmissivity tensor are calculated as 


$$
T_{i j}=\frac{1}{4 A^{e}}\left\{T_{x x} b_{i} b_{j}+T_{x y}\left(b_{i} c_{j}+c_{j} b_{i}\right)+T_{y y} c_{i} c_{j}\right\} .
$$

The boundary conditions are a pumping rate $Q$ in the well (node 1 )

$$
b_{1}=\int_{V} N_{1} r \mathrm{~d} V=-\frac{Q}{n} \int_{V} N_{1} \delta\left(\mathbf{x}-\mathbf{x}_{1}\right) \mathrm{d} V=-\frac{Q}{n} N_{1}\left(x_{1}, y_{1}\right)=-\frac{Q}{n}\left(1-\frac{0}{R \cos \alpha}\right)=-\frac{Q}{n},
$$

and the other two nodes have prescribed head, which is fixed to 0

$$
\left\{\begin{array}{l}
b_{2}=H_{2}=0 \\
b_{3}=H_{3}=0
\end{array}\right. \text {. }
$$

Imposing he boundary conditions and solving the system B.1 gives

$$
T_{11} h_{1}=b_{1}
$$

Solving A1.8 for $i=j=1$, and recalling B.9, the drawdown in the well given by the numerical simulation, $h_{l}$, is given by

$$
h_{1}=-\frac{Q}{n} \frac{1}{T \tan (\pi / n)} .
$$

To determine the apparent radius, $r_{a p}$, of the well that gives the same drawdown as the one given by the numerical model, $h_{n u m}$, the analytical expression for the drawdown given by Thiem (1906) is used

$$
h_{\text {num }}=h_{1}=\frac{Q}{2 \pi T} \ln \left(\frac{R_{e}}{r_{a p}}\right) \text {. }
$$

And operating from (B.13) gives the apparent radius

$$
r_{a p}=\frac{R_{e}}{e^{\frac{2 \pi}{n \tan (\pi / n)}} .}
$$

Note that for $n$ tending to infinity, the apparent radius reaches an asymptote equal to

$$
r_{a p}=\frac{R_{e}}{e^{2}}
$$

Finally, the numerical error due to the spatial discretization is 


$$
\varepsilon=h_{\text {Thiem }}-h_{\text {num }}=\frac{Q}{T}\left(\frac{1}{2 \pi} \ln \frac{R}{r_{w}}-\frac{1}{n \tan (\pi / n)}\right)
$$

where $R$ is the radius of influence and $r_{w}$ the actual radius of the pumping well.

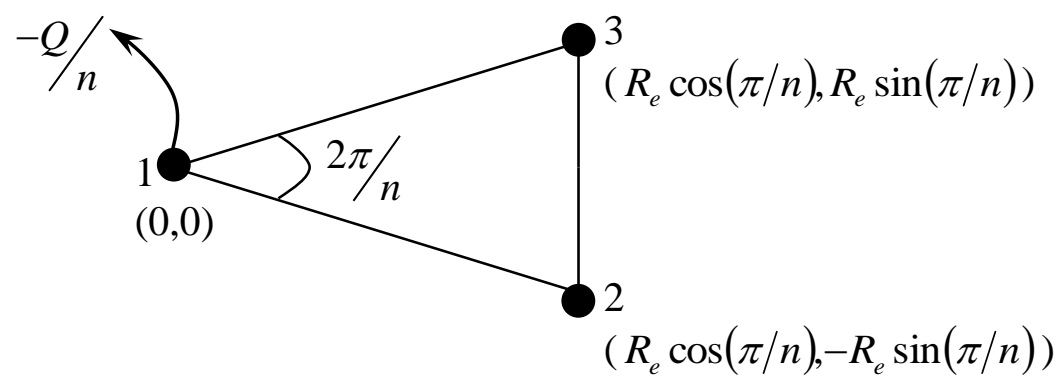

Figure B.1: One of the $n$ isosceles triangular elements that form the well (node 1), of size $R_{\ell}$, where a flow rate $Q$ is pumped. 